\title{
MÁS VALE PREVENIR QUE CURAR. PROPUESTAS PARA «CURAR» LA REORGANIZACIÓN QUE NO «PREVIENE» LA QUIEBRA
}

\author{
Nicola De Luca \\ Docente de Derecho de Quiebras de la Facultad de Derecho de la Seconda \\ Università di Napoli, Investigador de Derecho Mercantil \\ E-mail: ndeluca@luiss.it;nicola.deluca@unina2.it
}

\begin{abstract}
Resumen
En este artículo se identifican las causas que determinaron el fracaso: la atribución de la iniciativa para solicitar el concordato exclusivamente al deudor; la necesidad de presentar el proyecto junto con la propuesta; la actitud de la jurisprudencia en sede de admisión: sobre todo, la falta de incentivos para retrasar la negociación, mientras que la crisis aún no es dramáticamente irreversible, dentro de un procedimiento que protege contra el oportunismo de los individuos. En el escrito se formulan propuestas de carácter interpretativo y de reformas de la normativa vigente. Gracias a la teoría de juegos se reelaboran las razones que impiden el acceso al procedimiento y se propone resolver las ineficacias del modelo adoptado, al aplicar las soluciones que la experiencia comparada (sobre todo la americana, la alemana y la española) ofrece. Finalmente el artículo ofrece una serie de propuestas de reforma.
\end{abstract}

\section{Palabras clave}

Quiebra, incentivos, procedimiento, convenio anticipado, concordato preventivo.

\begin{abstract}
This article identifies the causes that led to the failure: the attribution of the initiative to request the concordat only the debtor;) the need to present the project along with the proposal, the attitude of jurisprudence based admission: especially, lack of incentives to delay the negotiations, while the crisis is not yet irreversible dramatically within a procedure that protects against opportunism of individuals. In the written proposals are formulated interpretive reforms and regulations. With game theory restate the reasons which prevent access to the procedure and aims to solve the inefficiencies of the model by applying solutions that comparative experience (especially the American, German and Spanish) offer. Finally, the article offers a series of reform proposals.
\end{abstract}

\section{Key Words}

Bankruptcy, incentives, procedure, convention advance arrangement with 

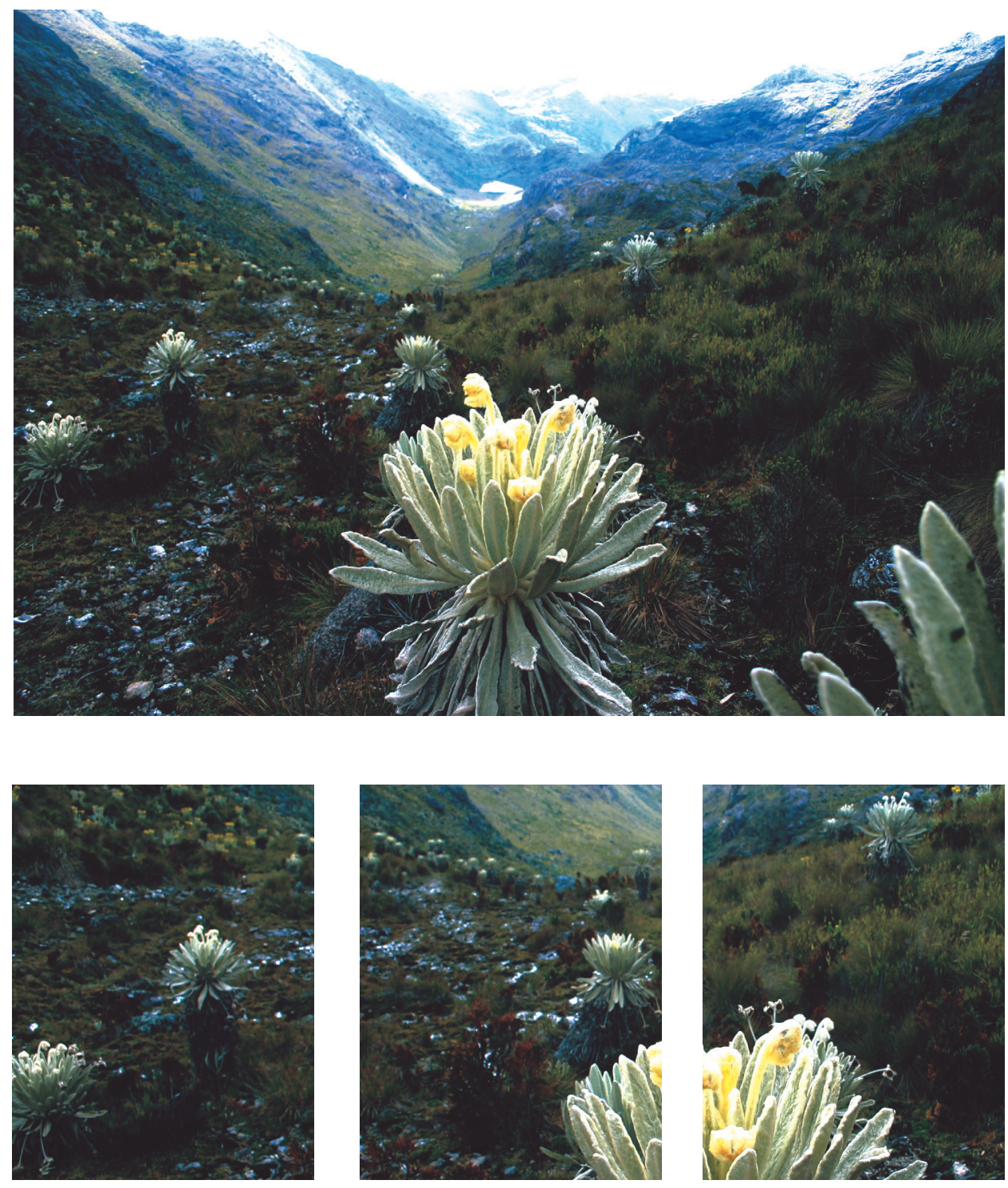

Camino a la "Laguna Colorada" 


\section{MÁS VALE PREVENIR QUE CURAR PROPUESTAS PARA «CURAR» LA REORGANIZACIÓN QUE NO «PREVIENE» LA QUIEBRA (")}

Nicola De Luca

\section{El concordato preventivo en el estudio sistemático de la ley de quiebras tras su reforma.}

Si bien la estructura de la ley de quiebras tras su reforma todavía considera la quiebra como el procedimiento básico y al concordato preventivo (que expresa una "propuesta anticipada de convenio" o "convenio anticipado") una alternativa, no resulta inapropiado creer que, después de la reforma, el orden lógico entre los dos procedimientos se ha de invertir, para comprender mejor sus características y utilización ${ }^{1}$. Desde un punto de vista sistemático, el concordato preventivo es

Este artículo apareció en italiano en Dir. Fall., 2010, I, 70. Para la redacción final, he aprovechado las apreciadas sugerencias de los Profesores Antonio Cetra, Gianmaria Palmieri, Vincenzo Pinto, Paolo Piscitello, Angel Rojo, Andrea Tucci, a quienes les agradezco muy sinceramente. Gracias, también, a Gabriele Nuzzo. La traducción al español es del autor, quien agradece la ayuda del prof. David Pérez Millán de la Universidad Complutense de Madrid y de José María Covelo, estudiante Erasmus de la Univerisidad de Enna Kore.

1 F. GUERRERA adopta correctamente esta perspectiva en Diritto Fallimentare - Manuale breve, por N. Abriani et al., Giuffrè, Milano 2007, pp. 131 y ss. Sobre la reforma del concordato preventivo, véase además, ex multis, S. AMBROSINI, Il concordato preventivo e gli accordi di ristrutturazione dei debiti, en Trattato di diritto commerciale, dirigido por G. Cottino, Cedam, Padova, 2008 (y v. también M. Vitiello, Il nuovo concordato preventivo: disciplina e primi problemi applicativi, ppp. 295 y ss.; S. Ambrosini, La domanda di concordato preventivo, l'ammissione alla procedura e le prerogative del Tribunale, pp. 315 y ss., en La riforma della legge fallimentare. Profili della nuova disciplina, por Ambrosini, Zanichelli, Bologna, 2006); varias contribuciones, en lo sucesivo citadas de forma separada, contenidas en Le soluzioni concordate delle crisi d'impresa, por G. Palmieri, Giappichelli Torino, 2007; L. GUGLIELMUCCI, Diritto fallimentare 3 , Giappichelli, Torino, 2008, pp. 311 y ss.; G. LO CASCIO, Il concordato preventivo ${ }^{7}$, Giuffrè, Milano, 2008; M. SANDULLI, sub art. 160, in La riforma della legge fallimentare, por A. Nigro e M. Sandulli, Tomo II, Giappichelli, Torino, 2006, pp. 980 y ss.; L. STANGHELLINI, Le crisi d'impresa fra diritto ed economia, Il Mulino, Bologna, 2007, pp. 117 y ss., 337 y ss.; G. TERRANOVA, Stato di crisi e stato di insolvenza, Giappichelli, Torino, 2007; M. VITIELLO, Procedure concorsuali - Concordato preventivo, en Il diritto-Encicl. giur., Milano, 2007, vol. XII, 30. 
considerado el procedimento que propende a la formación de un convenio ${ }^{2}$, con el fin del saneamiento o liquidación volontaria, capaz de impedir la quiebra de un empresario que tenga dificultades económicas (en condición de crisis). Por lo tanto, el concordato debería, sobre todo, tender a evitar la liquidación coactiva por parte de un administrador designado judicialmente, además de las consecuencias negativas de carácter personal y patrimonial que acompañan la quiebra y que, por lo menos hasta la reforma, eran extremamente severas para el empresario insolvente. A diferencia de las otras soluciones negociales, reguladas o simplemente mencionadas en la ley de quiebras (planes de saneamiento y acuerdos de reestructuración), que requieren un convenio ya establecido entre empresario y creedores ${ }^{3}$, el concordato preventivo, en cambio, es un procedimento que debería estar destinado a conformar un convenio. Si se considera la complejidad del remedio en función de la capacidad de resolver la crisis o de ponerle término, el concordato, por lo tanto, se coloca en un sector intermedio entre los acuerdos transaccionales y la quiebra. Los primeros deberían tender (exclusivamente) a la liquidación y hacer partícipes necesariamente a todos los acreedores, incluso los de un crédito que aún no es exigible. El concordato preventivo, en cambio, puede tender al salvamento o a la liquidación voluntaria. Es decir, tanto a la recuperación de la rentabilidad de la empresa sin significativas alteraciones en la estructura de la propiedad o conjuntamente a los programas de cesión del control o de la empresa, cuanto, en fin, a planes de desmantelamiento del conjunto empresarial para la satisfacción de los acreedores ${ }^{4}$.

2 O «transazione collettiva non negoziale ma procedimentale», según F. GUERRERA, en Diritto fallimentare, cit., p. 135.

3 Sobre las soluciones extrajudiciales, que no se tratan en este escrito, además de las citas de la nt. 3 véase también, L. BOGGIO, Gli accordi di salvataggio delle imprese in crisi-Ricostruzione di una disciplina, Giuffrè, Milano, 2007. Ya que el concordato surte efecto sobre todos los acreedores, pero non está vinculado a su consenso unánime, tendría que elegirlo el empresario que quiera evitar la quiebra cuando las soluciones extrajudiciales no pueden llevarse a la práctica, son demasiado difícil de negociar o su resultado es dudoso.

4 Con respecto a la negociación extrajiudicial, el concordato tiene por lo menos dos notas diferenciales significativas:

a) se articula según una secuencia de actos funcionales al conocimiento y aprobación del plan propuesto para superar la crisis o para liquidar la empresa; y b) se destina a producir efectos en todos los acreedores, aun prescindiendo del consenso individual. Algunos efectos, en cambio, son muy similares, pues los actos de ejecución del plan eluden igualmente la revocatoria (de quiebras) y se impiden las acciones ejecutivas individuales por parte de acreedores investidos por los efectos del convenio. Estos efectos se adelantan, en caso del concordato, a la presentación del recurso y, para los acuerdos de reestructuración, a la publicación del mismo (respectivamente, ex art. 168, párrafo $1^{\circ}$, y 182 -bis, párrafo $3^{\circ}$, ley de quiebras); hasta la homologación, los efectos de estos últimos se extienden también a los acreedores que no participan. Con respecto a la quiebra, el concordato se caracteriza fundamentalmente, por el carácter voluntario y por la (posible) finalidad de salvamento de la empresa (si que esta devenga de propiedad de sus acreedores) que no puede ser propio de un procedimiento exclusivamente liquidatorio. 
En consecuencia, los procedimientos y el concordato se deberían considerar soluciones alternativas entre sí en función de la necesidad de hacer partícipes a los acreedores, integral o parcialmente, en el objetivo común de evitar la liquidación coactiva. Mientras que la quiebra debería reconsiderarse como un conjunto de reglas con las cuales se realizará la liquidación si la negociación o el plan de saneamiento o de liquidación voluntaria no surtieran efectos o ni siquiera se intentasen. Y aunque es verdad que el inicio de la quiebra no impide en sí mismo una ulterior negociación entre el empresario y los acreedores (asimismo con la intervención de terceros ${ }^{5}$ ), también es verdad que a falta de un acuerdo que se haya alcanzado dentro de tiempos determinados y con las reglas previstas por la ley (es decir un concordato fallimentare), la sentencia declarativa actúa de manera que el procedimento se desarolle según un guión y un escenario predefinidos. Es decir, la liquidación del patrimonio, el reparto del remanente entre los acreedores y, en general, la eliminación de la empresa (y del empresario) del mercado. En el concordato fallimentare, por otra parte, el espacio para la negociación no es ilimitado y a esta altura el incentivo tiene un escaso valor ${ }^{6}$ : por un lado, la condonación de deudas se puede conseguir no obstante, por el otro lado, los efectos personales de la quiebra terminan con el decreto de cierre (art. 120 ley de quiebras), no con la rehabilitación civil como anteriormente.

No hay dudas de que la colocación sistémica del vigente procedimento de concordato preventivo - mucho más que la colocación «topográfica» en el ámbito de la ley de quiebras - se corresponde con la filosofía básica expresada por el legislador que delega a favor de la soluciones concordadas «alternativas a la quiebra». Soluciones que ya se han experimentado de manera positiva en otros sectores económicos y en otros países: en particular, la referencia remite al concordato de la "administración extraordinaria de las grandísimas empresas insolventes", introducido cuando se produjo el «crack Parmalat» (art. 4-bis d.1. 23 de diciembre 2003, n. 347), se imitó al denominado Chapter Eleven del Bankruptcy Code estadunidense y que se ha revelado eficaz, por lo menos en el caso Parmalat ${ }^{7}$.

\section{El Concordato preventivo en la praxis reciente.}

Esta que se acaba de exponer es, sin embargo, la teoría, según una síntesis breve y probablemente no precisa. Esa teoría no parece confirmarse plenamente en la praxis.

Ante todo, hay que considerar que las empresas que se pueden someter al

5 Esta cuestión la capta plenamente F. GUERRERA en Diritto fallimentare, cit., pp. 127-29.

6 Para reflexiones sugestivas, especialmente en materia de voto, v. F. D'ALESSANDRO, Il «nuovo» concordato fallimentare, en Giur. comm., 2008, I, 349.

7 El concordato en los procedimientos especiales de administración extraordinaria tiene el mismo contenido y finalidad que el concordato preventivo tras su reforma, pero, al igual que el concordato fallimentare, interviene de manera considerablemente diferente tanto desde el perfil procedimental como con relación al voto. Para una observación análoga L.GUGLIELMUCCI, Diritto fallimentare, cit., p. 317. 
procedimento de administración extraordinaria (ordinaria o especial) teóricamente podrían intentar un concordato preventivo análogo al que se puede proponer después de la apertura de la administración extraordinaria. Sin embargo, los casos recientes que tienen mayor eco prueban que esas empresas, de hecho, no apelan al concordato preventivo, al preferir entablar negociaciones reservadas o incluso públicas (son emblemáticos el caso Alitalia y el de la Tassara de Zaleski, ambos en la cresta de la ola en el 2008) con respecto a un procedimento judicial. La ventaja del procedimento judicial sería evidente, ya que el empresario o los administradores, en caso de sociedad, mantienen plenos poderes en orden a la negociación y la ejecución del concordato $^{8}$, a diferencia de lo que ocurre cuando se propone el concordato para luego conducirlo ex art. 78 d.lgs. 8, julio 1999, n.270 (en adelante «legge Prodi-bis»). En la administración extraordinaria de las grandísimas empresas (o procedimento especial), entre otras cosas, el comisario, y no el empresario, puede proponer el concordato ex art. 4-bis d.1. 23 diciembre 2003, n.347 (en adelante, decreto Marzano o Parmalat).

Esta actitud a nivel de las grandes y grandísimas empresas refleja, de hecho, la situación, que quizas no ha sido adecuadamente entendida en la reforma del concordato preventivo, de los empresarios italianos que todavía se resisten a considerar los procedimientos judiciales de carácter preventivo una «protección» contra la acción de los acreedores. En cambio, no por casualidad en los Estados Unidos se utiliza la expresión «to file for bankruptcy protection», que resulta irrelevante si se trata de un procedimento de reorganización o de liquidación (según, respectivamente, el Chapter 11 o 7) ( $\left.{ }^{9}\right)$. La protección contra la acción de los acreedores que actúan desde una perspectiva exclusivamente egoísta es necesaria para llegar a un acuerdo ventajoso, también para los mismos acreedores como categoría. La finalidad de todos los procedimientos de insolvencia, en primer lugar de la quiebra, es la de rechazar en el futuro y volver inefectivo en el pasado reciente el «ataque a la diligencia». Evidentemente, la actitud de los empresarios no se debe solamente a una dificultad de adaptación al contexto normativo que ha cambiado: parte de la responsabilidad se puede también atribuir a algunas imprecisiones de la introducción de la reforma que se pondrán en evidencia más tarde.

Por más que se disponga en pocos años y que no sean bastante detallados, los datos estadísticos no revelan una significativa reducción de las quiebras, ni tampoco un incremento de los concordatos preventivos relacionados con las mismas. Los datos Istat que se han difundido en octubre de 2008 - que se refieren al año 2006 y que, por

8 V. sobre esta cuestión G. TERRANOVA, Stato di crisi, stato d'insolvenza, incapienza patrimoniale, en esta Rivista, 2006, I, 547, y además en Stato di crisi e stato di insolvenza, cit., pp. 47 y ss.; y en Le soluzioni concordate delle crisi di impresa, cit., p. 16 (de donde se cita más adelante).

9 Sobre esta cuestión v. ultra $\S \S 4$ e 7. 
lo tanto, hay que interpretar con cautela, si se considera la entrada en vigencia de la reforma (que para el concordato debe adelantarse al año 2005) - indican un número de fracasos sustancialmente constante entre 2002 y 2006, que varía entre 10.192 en 2006 y 12.148 en $2005^{10}$. A una caída repentina en el 2007 (6.202), sin embargo, siguió un alza en el $2008(12.786)^{11}$. Un dato significativo es que de 10.192 fracasos declarados en 2006, 1.072, fueron pedidos por los deudores (el 10\%). Por otra parte el Istat no recoge los datos sobre el recurso al concordato preventivo, pero puede resultar útil tener en cuenta que de 13.260 fracasos, 134 (un modesto $0,1 \%$ ) fueron cerrados por concordato fallimentare en 2006 (de 12.726, 191 en el 2002; de 12.508, 164 en el 2003; de 13.260, 194 en 2004; de 13.174, 147 en 2005; y de 12.320, 134 en 2006). Una investigación parcial, llevada a cabo de manera independiente sobre el Tribunal de Venecia, señala que los concordatos preventivos admitidos desde 2004 hasta diciembre 2007, fueron respectivamente 5 en 2004, 11 en 2005, 9 en 2006, 4 en 2007, mientras que los fracasos declarados fueron respectivamente 134 en 2004, 197 en 2005, 151 (156 según el Istat) en 2006, 110 (dato estimado; en septiembre eran 73) en $2007^{12}$. Y si bien otros datos relativos al primer semestre 2009 parecen indicar un recurso creciente al concordato preventivo, es evidente que el mismo sigue siendo irrisorio en términos de porcentajes con respecto al número de fracasos ${ }^{13}$.

A partir de un simple análisis de los datos indicados resulta que hay pocos concordatos preventivos (desde un $0,5 \%$, en la mayoría de los casos, hasta un máximo de $2,5 \%$ de los fracasos declarados) y que, si se tiene en cuenta el número relativamente alto de solicitudes de quiebras por parte de los deudores (el 10\% de los fracasos declarados), las empresas no los consideran aún un medio eficaz para evitar el fracaso. Además, también los concordati fallimentari resultan ser muy pocos (el $0.1 \%$ de los fracasos cerrados). A la inversa, si el dato de los fracasos declarados por iniciativa de los empresarios en crisis fuera de cualquiera manera sintomático de una actitud de colaboración $y$, por lo tanto, de una tendencia del empresario hacia una solución concordada (que tiende al saneamiento o a la cesión de la empresa), cabría considerar que la finalidad del legislador de reducir el número de fracasos, al promover las soluciones concordadas, se puede alcanzar. Pero será necesario generar la percepción de que el concordato puede ser una ventaja sustancial tanto para el empresario que propone como para los acreedores. Hay que considerar también que si hay una disminución de fracasos declarados en los próximos años, como en el

10 Fuente: Istat, localizable en http://www.istat.it.

11 Fuente: cámaras de comercio; datos difundidos por Il Sole 24 ore de 26 de enero de 2009, con comentario de E. SCARCI, I fallimenti sono raddoppiati nel 2008.

12 Fuente: CESDOC, disponible en http://www.odcvenezia.it/cesdoc/.

13 Fuente: CERVED; il dato, difundido por Il Sole 24 Ore de 3 Agosto de 2009, se atiene a las sociedades de capitales, señala un crecimiento constante desde 2002 y un salto de los 309 de 2008 a los 366 del primer semestre 2009. 
2007, esto se deberá a otro motivo, es decir, la renovada definición de los requisitos ${ }^{14}$, que implica una significativa erosión del "area della fallibilitá" para las empresas de dimensiones más pequeñas ${ }^{15}$ : pero eso no se corresponderá necesariamente al descenso de la intervención judicial en sede de ejecución ${ }^{16}$.

En conclusión, el concordato preventivo tras su reforma no previene el agravamiento de la crisis y no evita la quiebra con los costes que se relacionan a esa misma. Si todos han acogido la reforma de la ley de quiebras desde la perspectiva de un mayor recurso a los procedimientos alternativos y en particular al concordato preventivo, un primer balance de la reforma, en cambio, es irónicamente "un fracaso". Entonces, es necesario preguntarse qué determina este resultado y qué impide la difusión de este procedimiento, y consagrarse a formular propuestas para sugerir las correcciones o interpretaciones que pueden resultar adecuadas. Tal como enseñaba Hipócrates, que ha sido retomado por una eficaz réclame hace unos años atrás: más vale prevenir que curar.

\section{Buscando las razones del fracaso.}

Más allá del problema, que a corto plazo no se puede superar fácilmente, de la actitud muy común entre las empresas, las causas que parecen determinar el fracaso del concordato preventivo que se ha registrado están esencialmente relacionadas con el acceso al procedimiento y a la formulación de la propuesta de concordato. En primer lugar, la admisión al procedimiento, capaz de garantizar la protección contra las acciones ejecutivas de los acreedores se antoja lenta y exageradamente diferida, tanto que no son factibles en su mayoría los planes que tienden al saneamiento de las empresas, que en un $70 \%$ llegan al Tribunal muertas, «sin ninguna actividad $»^{17}$.

14 Sobre esta cuestión, las interesantes reflexiones de M. CAMPOBASSO, Il piccolo imprenditore (...) da una riforma all'altra, en Temi del nuovo diritto fallimentare, por G. Palmieri, Giappichelli, Torino, 2009, pp. 1 y ss., espec. 7; y además F. ACCETTELLA, Il piccolo imprenditore ed il nuovo art. 1 della legge fallimentare, en Banca, borsa, tit. cred., 2007, I, 721.

15 Al respecto, no se puede olvidar, por otra parte, la discutible solución de conservar con carácter unitario los requisitos subjetivos de acceso a la procedura insolvencia y al concordato preventivo, al impedir a los «pequeños empresarios» de acogerse a una solución concordada de carácter judicial. A falta de un procedimiento de insolvencia para los deudores comunes y para los empresarios no sometidos a la quiebra y al concordato preventivo - aspecto que hoy en día está pendiente en el Parlamento, como consecuencia de la enmienda propuesta el 14 de enero de 2009 por el sen. Centaro, de acuerdo con el Ministerio de Justicia: v. artt. 7-22 DDL «Disposizioni in materia di usura» n. 307/2009, disponible en http://www.senato.it - resulta fundada la sospecha de que la Corte Constitucional pueda verse implicada al tener que juzgar la conformidad con respecto al principio de igualdad de esta regla (y de la que permite el acceso al beneficio de la "esdebitazione" sólo a los empresarios que pueden aceder a los procedimientos de insolvencia).

16 Y v. sobre este aspecto G. DELLA PIETRA, Innalzamento delle soglie di fallibilità e ritocchi al processo esecutivo: di alcune asimmetrie e consonanze, en Temi del nuovo diritto fallimentare, cit., pp. 69 y ss.

17 De Il Sole-24 Ore de 3 agosto de 2009, p. 15. 
A menudo, la jurisprudencia no renuncia a un control de fondo sobre los términos de los planes propuestos y la revisión del presupuesto objetivo - el estado de "crisis" - no parece que haya concurrido a que se anticipe la intervención ${ }^{18}$. En segundo lugar, la estructura actual del procedimiento por iniciativa del solo deudor y en forma "preempaquetada» (c.d. pre-packaged bankruptcy) ${ }^{19}$ impide márgenes sustanciales de negociación entre empresario y acreedores antes del voto, de modo que no permite modificar de manera sustancial el plan ${ }^{20}$ e impone a los acreedores menores soluciones de «tomar o dejar» formuladas con el concurso - o a tener en cuenta sólo las pretensiones - de los acreedores fuertes. Respecto de otros aspectos, de cualquier modo, también la escasa coordinación con la disciplina del concordato fallimentare contribuye a la incertidumbre sobre la eficacia del remedio. Sin duda, la objetiva, deplorable redundancia legislativa - los quince artículos dedicados al concordato fallimentare se reproducen casi servilmente en más de 25 artículos dedicados al concordato preventivo, que siguen y no preceden a los primeros ${ }^{21}$

18 Constituye una opinión extendida, sobre todo con referencia a la posible realización del plan, que el control del Tribunal sólo tiene que ser de legalidad: v. en este sentido A. JORIO, Le soluzioni concordate delle crisi d'impresa tra «privatizzazione» e tutela giudiziaria, in Fall., 2005, 1453, ivi en la p. 1456; A. PALUCHOWSKI, I poteri del tribunale in sede di ammissione e nel corso della procedura di concordato preventivo con particolare riferimento alle ipotesi di conversione della procedura in fallimento, en esta Rivista, 2006, I, 1147; L. STANGHELLINI, Le crisi d'impresa tra diritto ed economia, cit., p. 133; y además G. NUZZO, I poteri del Tribunale nel concordato preventivo, Tesis de doctorado en derecho mercantil de la Università di Catania, XIX ciclo, octubre, 2008, consultada gracias a la cortesía del Autor. Esta orientación, de hecho, se debe por un lado por la jurisprudencia: por ejemplo, Appello Milano, 4 ottobre 2007, en Dir. Fall., 2008, II, 317; Tribunale Milano, 9 de febrero de 2007, en Fall., 2007, 1218, pero todavía resulta discutida por otro lado: v. Tribunale Roma, 8 de marzo de 2006, en Dir. e pratica fallim., 2006, fasc. 4, 54. En general v. sobre el punto S. SCARAFONI, Il giudizio d'ammissione al concordato preventivo: riflessioni sul decreto legislativo correttivo della legge fallimentare, en Dir. Fall., 2007, I, 902.

19 Lo que quiero subrayar en el texto es que no sólo hace falta hablar de soluciones preempaquetadas cuando de hecho el deudor obtuvo el consentimiento de la mayoría de los acreedores (a lo mejor a través de un convenio extrajudicial) y va a imponer el plan también a los acreedores ajenos, a través del procedimento judicial; pero hay que ¿cabla? de esto para todos los accesos al concordato, ya que hay que presentar el plan junto con la solicitud y, por tanto, exista o no el acuerdo con la mayoría de los acreedores, esto es el «paquete» que hay que probar o rechazar. En Italia L.STANGHELLINI expone esta cuestión en, Le crisi d'impresa tra diritto ed economia, cit., pp. 325 y ss., que subraya, de hecho, que la previsión que impone la presentación del plan junto con la solicitud de admisión haga «más difícil y retrase la apertura del procedimiento». Sobre el punto v. también G. PRESTI, Gli accordi di ristrutturazione dei debiti, in Banca, borsa, tit. cred., 2006, I, 16, ivi a p. 21.

20 La duda nace, en particular, respecto de las modificaciones in pejus. Y v., aunque requiera una información apropriada,Tribunale Ancona, 23 maggio 2007, in Fall., 2008, 231; contra Tribunale Sulmona, 5 dicembre 2007, in Fall, 2008, 822; M. VITIELLO, Il nuovo concordato preventivo: disciplina e primi problemi applicativi, cit., pp. 301 y ss. Secondo Tribunale Palermo, 18 de mayo de 2007, en Fall., 2008, 75, la modificación de la propuesta no hace «necessaria una nuova relazione del professionista ai sensi dell'art. 161 legge fallim. ed un'ulteriore valutazione di ammissibilita' ai sensi dell'art. 163 legge fallim.».

21 Para una comparación F. GUERRERA, en Diritto fallimentare, cit., p. 128. 
dio lugar hace tiempo a considerables incertidumbres en cuanto a la interpretación (ahora probablemente resueltas). Pero además de éstas, algunas cuestiones cruciales de coordinación siguen sin resolverse junto con las dudas en materia de sucesión de los procedimientos ${ }^{22}$. Por un lado, en caso de fracaso de la negociación o de rechazo de la propuesta, alguien (acreedores o el fiscal) siempre tiene que tomar la iniciativa de iniciar el procedimento de quiebra ex novo, con una posible solución en la continuidad en el tratamiento de la crisis que no parece motivada, ni tampoco se puede explicar a partir de la voluntad legislativa de privar al juez del poder de declarar de oficio el fracaso. Por otro lado, no se explica de manera adecuada el motivo por el cual se excluye la aplicación al concordato preventivo del mecanismo de votación proprio del concordato de quiebra y del de la administración extraordinaria especial: mecanismo que sin duda se ha revelado una manera más eficaz para la formación del convenio $^{23}$. Por último, no hay dudas de que la tímida admisión del tratamiento no integral de los acreedores privilegiados también en el concordato preventivo, en un sistema en que los privilegios generales y especiales son la regla y no la excepción, disminuye muchísimo las posibilidades de éxito ${ }^{24}$.

22 Dudas que la jurisprudencia seguramente podrá superar, si se tiene en cuenta la orientación consolidada, según la cual también la admisión al cerrado procedimento de administración controlada, basado en la dificultad temporal, a diferencia del concordato y del fracaso, se podía considerar relevante para el dies a quo en las acciones revocatorias en caso de sucesivo fracaso: y v. en fin Cassazione, sez. I, 28 de novembre de 2008, n. 28445, en Rep. Foro it., 2008, voce Fallimento [2880], n. 458; Cassazione, sez. I, 3 de novembre de 2005, n. 21326, en Dir. e pratica fallim., 2006, fasc. 5, 40. En la doctrina v. A. AMATUCCI, Temporanea difficoltà e insolvenza, Liguori, Nápoles, 1979.

23 La aprobación del concordato se realiza por mayoría, general o por clases, pero quien no se expresa se considera como si hubiera aprobado: art. 128 ley de quiebras. e 4-bis d.1. 347/03. A favor de un mecanismo formativo del consenso en que quede firme la regla de mayoría propia del concordato preventivo, aún en los otros concordatos, se expresa en cambio, F. D’ALESSANDRO, op. cit., p. 351.

24 Después de la intervención correctiva, el plan del concordato (también en el concordato preventivo) puede contemplar la satisfacción no integral de los créditos que gocen de privilegio, prenda o hipoteca. Según lo que ya ha sido dispuesto para el concordato de quiebras, la ley impone que el plan prevea la satisfacción en medida no inferior a la realizable, a razón de la colocación preferencial, sobre el provecho en caso de liquidación, al haber considerado el valor del mercado atribuible a los bienes o derechos sobre los cuales hay la causa de tanteo. Hay que señalar el valor del mercado de los bienes en la relación jurada de un profesional idóneo para estimar la sensatez de un plan de saneamiento para la exención de revocatoria (art. 67, comma $3^{\circ}$, lettera $d$, legge fallim.). Se puede colocar a los acreedores privilegiados en clases homogéneas para la votación. La cuestión recibió amplia consideración en doctrina y jurisprudencia antes del d.lgs. 12 de septiembre de 2007, n. 169 (c.d. «correttivo»), ya que la solucción que ahora se extiende al concordato preventivo se preveía expresamente para el de quiebras, y ya que por lo menos uno de los acreedores privilegiados, el fisco, podía ser objeto de pago parcial también en sede de concordato preventivo o convenio de reestructuración, a través de la transacción fiscal ex art. 182- 
ter legge fallim. (v. en una posición opuesta, C. FERRI, I crediti privilegiati nella disciplina del nuovo concordato preventivo, en Fall., 2006, 695; D. GALLETTI, sub art. 160, en Il nuovo diritto fallimentare, comentario dirigido por A. Jorio y coordinado por M. Fabiani, pp. 2288 y ss.; G. LO CASCIO, Il concordato preventivo, Milano, 2007, pp. 2267 y ss., y en síntesis S. AMBROSINI, Il concordato preventivo e gli accordi di ristrutturazione dei debiti, cit., pp. 47-54). La predominancia de la solución permisiva era de esperar, pero de ninguna manera se previó (v. Tribunale Torino, 20 de diciembre de 2006, en Fall., 2007, 431, con nota de CENSONI; Tribunale Verona, 13 de octubre de 2006, en Fall., 2007, 665; contra, entre otras, Tribunale Roma, 23 de octubre de 2006, en Fall., 2007, 47; en esta Rivista, 2008, II, 325, en el famoso caso de la Finmavi di Cecchi Gori, admitida al concordato y luego declarada en quiebra por la iniciativa del mayor acreedor, Merryl Lynch) a falta de una corrección legislativa (exactamente, M. VITIELLO, Il nuovo concordato preventivo: disciplina e primi problemi applicativi, cit., pp. 308 y ss.). La condición a la que el legislador ahora subordina la posibilidad de ofrecer un pago parcial a los acreedores privilegiados es que se reserve a los mismos un tratamiento no inferior a lo que recibirían al liquidar a valor de mercado el bien sobre el que recae la garantía. La regla por supuesto se contempla para las garantías específicas (prenda, hipoteca, y privilegio especial) ya que sólo para estas es posible establecer comparativamente un valor de mercado del bien objeto de la garantía (y v. las justas observaciones de S. AMBROSINI, Il concordato preventivo e gli accordi di ristrutturazione dei debiti, cit., pp. 56 y ss.). Esta norma, por otra parte, tiene una importancia muy diferente con respecto a la otra en materia de homologación del concordato para clases, que permite la oposición cuando el tratamiento de una clase (disidente) y comparativamente peor con respecto a las alternativas que pueden practicarse en concreto. En verdad, cada vez que el valor estimado de la venta es por lo menos igual al crédito, la satisfacción de los acreedores privilegiados tiene que ser integral. La satisfacción parcial, pues, puede afectar sólo al eventual remantente, respecto del que, sin embargo, hay que comparar al acreedor que tiene una garantía especial insuficiente con un quirografario. Por otro lado, el tratamiento que se reserva a los acreedores privilegiados en el concordato preventivo en ningún caso puede ser peor con respecto al de las alternativas que en abstracto se pueden practicar, porque la única verdadera alternativa es la de la venta en la quiebra o en un procedimiento forzoso judicial (sobre esta cuestión otra vez S.AMBROSINI, Il concordato preventivo e gli accordi di ristrutturazione dei debiti, cit., p. 57). La venta en el fracaso, aunque ahora evita cuanto más a la lentitud y a la ineficiecia de las ventas judiciales, sin embargo descuenta el precio de los gastos de procedimiento que se van en prededucción y que hay que pagar con prioridad absoluda. En el fondo, se trata de una norma que permite exclusivamente evitar (el absurdo) de ofrecer necesariamente a los acreedores privilegiados el pago integral aun cuando el valor del mercado del bien sobre el cual recae la garantía no lo permite (por otro lado, si los bienes tienen un valor insuficiente y no se ofrece un pago porcentual, el concordato se resuelve al no poder aplicarse el art. 54 ley de quiebras: Tribunale Piacenza, 8 de febrero de 2008, Fallimento \& crisi impresa, 2008, 605). Quizás una mejor solución (sobre todo para el concordato de quiebras) sería la de imponer un pago no inferior, que los acreedores privilegiados cobrarían en caso de liquidación de quiebras o después de una venta judicial (en el presupuesto, lógicamente, que el experto sea capaz de señalarlo), en vez del valor de mercado, y permitir al plan de proponer un pago porcentual para un remanente mayor. Además se ha propuesto (G. NUZZO, I poteri del Tribunale nel concordato preventivo, cit., pp. 159 y ss.; ahora Id., Creditori privilegiati: soddisfatti pienamente ma non pagati integralmente, de próxima publicación en Banca, borsa, tit. cred., II) interpretar la expresión soddisfazione non integrale en el sentido de que sería aceptable una satisfacción de los acreedores privilegiados que difiera del pago (por ejemplo convirtendo sus créditos en acciones u obligaciones por un igual valor nominal). Con la consecuencia de que los acreedores privilegiados en este caso serían admitidos a la votación para la totalidad, al no cobrar pago integral (así se expresa el art. 177, comma $2^{\circ}$, ley de quiebras.). La solución es interesante y 
Más adelante voy a señalar reflexiones sobre algunos de esos asuntos, sin ninguna pretensión de agotar los temas, sino solamente con la ambición de abrir una discusión crítica y constructiva. Iniciaré el discurso a partir de la nueva definición del presupuesto objetivo del concordato - el estado de crisis - que hubiera debido facilitar una intervención anticipada $\mathrm{y}$, por lo tanto, más eficaz sobre las empresas en condiciones de dificultad, pero que no ha sido apreciada por la práxis, por no conseguir el resultado esperado (párrafo 4-5). Después pondré en discusión la oportunidad de un examen judicial profundizado en la admisión al concordato, para concluir que cuanto más pequeña es la intervención del juez, más altas son las probabilidades del éxito de los procedimientos que tienden genuinamente a la reestructuración de las empresas en dificultad (párrafo 6). Una vez expuestas las reflexiones de lege lata concluiré con algunas modificaciones de lege ferenda. De hecho me preguntaré sobre la oportunidad de mantener la iniciativa para la admisión al concordato (preventivo) exclusivamente con el deudor, trayendo a colación la experiencia de otros ordenamientos en que, en cuanto se verifica la crisis, la elección del remedio adecuado se remite a todos los interesados durante el procedimento y no a su exterior, incluso a precio de una modificación coactiva de la estructura de la propiedad (en el complejo empresarial destinado a salvarse) (párrafo 7).

\section{El estado de crisis.}

¿De qué puede servir el concepto? - El último apartado del artículo 160 ley de quiebras plantea una cuestión que, hasta ahora, ha sido mucho más teórica que práctica; se precisa que por estado de crisis se entiende también el estado de insolvencia. La norma, introducida con urgencia (art. 36 d.1. 237/05) para resolver la duda que ha surgido en la jurisprudencia y en parte de la doctrina ${ }^{25}$, tiene la intención de aclarar que la insolvencia no obstruye el acceso al procedimiento, ni que sea factible alguno de los programas que el procedimiento puede perseguir, entre ellos, el saneamiento. La solución es coherente con lo que se prescribe en materia de

literalmente aceptable (tanto que se acepta en lo sustancial, si bien con referencia a la satisfacción dilacionada de los privilegiados, por el Tribunale Catania, 27 de julio de 2007, en Giur. comm., 2008, II, 677, con nota a favor de E. MACRİ, que los admite a la votación por la totalidad). Si, sin embargo, por efecto de la satisfacción por otro medio, los privilegiados pierden la garantía (y de hecho, se abarca el hecho de que las obligaciones pueden ser especificamente garantizadas, las acciones no pueden serlo) tendrán una motivación fundada para votar en contra, y si el plan propone pagar los quirografarios con los bienes sobre los cuales recae la garantía, podrán impugnar que se ha alterado el orden legal de las causas de tanteo.

25 Erróneamente, Tribunal Alessandria, 7 de junio de 2005, en Giur. it. , 2006, 990; Tribunal Florencia, 23 de noviembre de 2005, en Foro toscano-Toscana giur. , 2006, 59; Tribunal Treviso, 22 de julio de 2005, en Dir. Fall., 2006, II, 102, con nota de G. NUZZO, Primi orientamenti giurispruden₹̨iali in tema di concordato preventivo; correctamente, Tribunal Sulmona, 6 de junio de 2005, en Fall., 2005, 793, con nota de G. BOZZA, L'organo deputato alla verifica della maggioranza nel nuovo concordato. 
administración extraordinaria de las grandes empresas en estado de insolvencia y que, a pesar de ello, pueden perseguir programas de saneamiento ${ }^{26}$.

Es bastante evidente cuál puede ser la utilidad de emplear una noción de crisis diversa de la insolvencia, pero que la contenga. Si es verdad que las operaciones de salvamento de las empresas en dificultad son más eficaces si se recurre a ellas lo antes posible, es comprensible que no se ha de esperar a una situación de crisis grave - como es, hasta intuitivamente, la insolvencia - para proponer un convenio a los acreedores. La referencia a la crisis implica que se prohíbe, sin duda, proponer al deudor un convenio cuando no existe la crisis. Pero no es fácil inferir algo más. No está claro, en efecto, si se puede hablar de crisis aun cuando ésta todavía no se ha revelado, pero se dan todos los índices que permiten presumirla; cuando hay crisis, pero puede superarse sin la necesidad de un acuerdo con los acreedores; o bien, cuando se refiere a las perspectivas a la largo plazo de la empresa, es decir, su capacidad de mantener la cuota de mercado. O, por fin, puede valer la pena preguntarse si el ordenamiento puede conceder al deudor (y a los acreedores que tienen mayor interés) una ventaja para implicar toda la clase de acreedores en un tratado que, eventualmente, podría devenir extrajudial y sin efectos universales: se recuerde, de hecho, al mismo concepto de crisis se refieren tanto el artículo 160 ley de quiebras en materia de convenio preventivo, como el artículo 182-bis ley de quiebras en materia de acuerdos de reestructuración ${ }^{27}$. Es evidente que la reflexión ha de centrarse en estas situaciones «border-line» ya que son aquellas en las que, con mayor probabilidad, una intervención precoz puede ser también eficaz, para permitir la recuperación de un complejo empresarial todavía eficiente.

26 V., no obstante, S. AMBROSINI, Il concordato preventivo e gli accordi di ristrutturazione dei debiti, cit., p. 24.

27 Teóricamente nada impide al acreedor contrario demostrar que el plan de saneamiento habría podido realizarse sin reducción de su posición, con la implicación de, por lo menos, un sesenta por ciento de acreedores que lo aprobaran. Pero, por una parte, la pruebra se antoja diabólica y, por otra, podría ser insuficiente. Si se está de acuerdo con la tesis de que la crisis es el presupuesto tanto para el acceso al convenio preventivo como para el acuerdo de reestructuración, su inexistencia justifica que los acreedores se opongan, pero no que fiscalicen la oportunidad del remedio. De hecho la ley habla de idoneidad del plan para superar la crisis, pero no de adecuación o de proporcionalidad, confiando en el hecho de que un plan que ofrece porcentajes demasiado bajos será rechazado por los acreedores. En este sentido, puede despertar sospechas, pero no creo que puede impedirse la ejecución de un acuerdo de reestructuración aprobado, por lo menos, por el 60 por ciento de los acreedores (dando adecuada garantía a los acreedores externos del pago puntual e íntegro) que prevé a cargo del deudor la obligación de proponer un convenio sobre un diferente plan preconfeccionado, que los mismos acreedores mayoritarios aprobarán, de modo que se implique también a los acreedores ajenos al acuerdo de reestructuración. De la relación entre los acuerdos de reestructuración y crisis se ha ocupado, por último, A. CARLI, Accordi di ristrutturazione dei debiti ed impresa in crisi, en Contratto e impr., 2009, 410. 
Desde este punto de vista, es necesario aclarar, en concreto, qué es la crisis. En torno a esta cuestión no falta la literatura, no solo jurídica ${ }^{28}$, no obstante muy incierta, también por la dificil coordinación con la noción de insolvencia, de la que, sobre todo en pasado, se han dado definiciones muy elásticas ${ }^{29}$. No parece conviencente ${ }^{30}$ la distinción común tanto en la doctrina como en la jurisprudencia, basada en el carácter reversible del estado ${ }^{31}$, ya que tampoco la insolvencia evidente impide los procedimientos de saneamiento. Más eficaz es otra definición común en la jurisprudencia según la cual, mientras que la insolvencia es una «situación de impotencia económica funcional y no transitoria», la crisis también puede consistir en otras situaciones de menor gravedad ${ }^{32}$ : por ejemplo, el peligro de insolvencia (habla de drohende Zahlungsunfähigkeit el $\S 18$ InsO alemana y de insolvencia inminente, el art. 2 ley concursal española $)^{33}$ y, por lo general, el descenso del capital por debajo

28 Parte de la doctrina económica se centra en el equilibrio económico. Según VERGARA, Disfun₹ioni e crisi d'impresa. Introduzione ai processi di diagnosi, risanamento e prevenzione, Milano, 1988, pp. 46 y ss., se habla de crisis y no ya de mera disfunción, cuando la empresa no es capaz de satisfacer las condiciones que regularizan su equilibrio económico. Otra parte de la doctrina ha articulado con más esmero el análisis del proceso degenerativo, que distingue entre decadencia, crisis, insolvencia y ruina. Según GUATRI, Crisi e risanamento dell’impresa, Milán, 1986, pp. 11 y ss.; y más recientemente, PICIOCCHI, Crisi d’impresa e monitoraggio di vitalità, Turín, 2003, pp. 13 y ss., hay «crisis» cuando las pérdidas falsifican el equilibrio financiario y patrimonial de la empresa. Ni una ni otra concepción, sin embargo, parecen definitivas en el sentido de una mejor localización de los umbrales de acceso a los procedimientos concursales.

29 Recientemente, v. G.B. MACRÍ, en Le soluzioni concordate delle crisi d'impresa, cit. pp. 66 y ss.; A.M. AZZARO, Le funzioni del concordato preventivo tra crisi e insolvenza, en Fall., 2007, 741; y para algunas implicaciones sobre la coordinación con la concepción civilista de insolvencia, F. MACARIO, Insolvenza, crisi d'impresa e autonomia contrattuale. Appuntiper una ricostruzione sistematica delle tutele, in Riv. soc., 2008, 102. sobre el concepto de insolvencia antes de la reforma, se envía a la extensa contribución por G. TERRANOVA, Lo stato di insolvenza. Per una concezione formale del presupposto oggettivo del fallimento, in Giur. comm., 1996, I, 82, a pp. 92 (reeditado en ID., Stato di crisi e stato di insolvenza, cit., pp. 1 y ss.), para quien la noción de insolvencia coincide con el hecho de «no ser capaz más de satisfacer regularmente las propias obligaciones»; al respecto los índices exteriores de comma I del artículo 5 ley de quiebra son presuntivos y no constitutivos.

30 Conforme S. AMROSINI, Il concordato preventivo e gli accordi di ristrutturazione dei debiti, cit., p. 27.

31 V. por todos, G.F. CAMPOBASSO, Diritto commerciale, III, Contratti, titoli di credito, procedure concorsuali ${ }^{4}$, Utet, Turín, 2008, pp. 335, 413, donde pueden encontrarse algunas referencias.

32 En este sentido Tribunal Palermo, 17 de febrero de 2006, en Fall., 2006, 570; por la noción de insolvencia como situación de impotencia económica funcional y no transitoria v. Casación, 21 de noviembre de 1986, n. 6856, en Fall., 1987, 190; Casación, 14 de marzo de 1985, n. 1980, en Giur. Comm.., 1985, II, 45; Casación, 11 de mayo de 1981, n. 3095, en Giur. comm., 1982, II, 463; Apelación Génova, 28 de abril de 2004, en Dir. Fall., 2005, II, 99; Tribunal Tivoli, 3 de jenero de 2003, en en Dir. Fall., 2004, II, 327; Tribunal Nápoles, 17 de mayo de 2000, en Dir. e Giur., 2000, 402.

33 Se puede enviar, por la noción expresa en la ley alemana en Ulrich SCHMERBACH, vor § 18, en Frankfurter Kommentar zur Insolvenzordnung, 5. Aufl, herausgegeben von Klaus Wimmer, Luchterhand, Köln, 2009, pp. 264 y ss.; Jochzen DRUKARCZYK, vor § 18, en Münchener 
del mínimo legal ${ }^{34}$. Sin embargo, todas estas situaciones de menor gravedad - con excepción de las patrimoniales típicas de las sociedades ${ }^{35}$ - no se prestan, mejor que la insolvencia, a ser definidas. Por lo tanto, no facilitan la tarea de quien tiene que juzgar si un plan de saneamiento incluído en una propuesta de convenio, puede acogerse a los beneficios de la ley (es decir: bloqueo de las acciones ejecutivas individuales, exención de una futura revocatoria, sometimiento de los contrarios minoritarios a la voluntad de la mayoría) o si se ha de satisfacer la petición de uno o más acreedores de rechazar la propuesta porque no concurran los presupuestos.

También en el americano common law la jurisprudencia lleva a cabo una distinción entre insolvency y zone of insolvency ${ }^{36}$, que, sin embargo, no tiene valor a los efectos del acceso a los procedimientos concursales de reorganization o liquidation; sino que se elabora para adelantar el momento en que los llamados fiduciary duties de los administradores de la sociedad «solvent, but in the zone of insolvency» deberían

Kommentar. Insolvenzordnung, Band 1, 2. Aufl., Beck, München, 2007, pp. 446 y ss., donde extensas referencias de literatura. Según el artículo 2 Ley concursal española: «se encuentra en estado de insolvencia inminente el deudor que prevea que no podrá cumplir regular y puntualmente sus obligaciones». V. Ángel ROJO, sub art. 2, en Comentario de la ley concursal por Ángel Rojo y Emilio Betrán, Civitas, Madrid, 2004, Tomo I, pp. 164 y ss., el cual nota que si bien el presupuesto para el acceso a los procedimientos sea único (la insolvencia) en realidad la ley provee tres acepciones: la insolvencia inminente; la insolvencia actual; la insolvencia cualificada. Sería inminente, según el A. citado, la insolvencia del «deudor que prevea la imposibilidad de cumplir como objetivamente probable acorto plazo». Id., en p. 176.

34 L. GUGLIELMUCCI, Diritto fallimentare, cit., pp. 313 y ss.

35 Es causa de apertura del concurso, en Alemania, el c.d. desequilibrio patrimonial (Überschuldung) del cual al $\S 19$ Ins $O$ alemana. Se trata de una situación del todo emparada a la insolvencia, si no es índice de ella. Y v. Ulrich SCHMERBACH, vor $\S 19$, en Frankfurter Kommentar zur Insolvenzordnung, 5. Aufl., herausgegeben von Klaus Wimmer, Luchterhand, Köln, 2009, pp. 271 y ss.; Jochzen DRUKARCZYK, vor § 19, en Münchener Kommentar. Insolvenzordnung, Band 1, 2. Aufl., Beck, München, 2007, 464 ss., donde extensas referencias de literatura.

36 Uno de los primeros casos es Federal Deposit Insurance Corp. v. Sea Pines Co., 692 F.2d 973, 976-77 (4th Circ. 1982). Las dificultades de individuación de los límites de la zone of insolvency aparecen con particular evidencia en Production Resources Group, L.L.C. v. NCT Group, Inc., 863 A.2d 772, 789 nt. 56 (Del.Ch. 2004):

"[T] he 'zone' issue is an admittedly confusing one. [...] The more difficult issue is whether there is a zone in which the directors' duties to the firm fundamentally change and whether creditors can assert fiduciary duty claims (e.g. for injunctive relief) before the firm becomes insolvent. If creditors have standing to bring derivative claims in the 'zone of insolvency,' they will share that standing with stockholders, leading to the possibility of derivative suits by two sets of plaintiffs with starkly different conceptions of what is best for the firm. Defining the 'zone' for these purposes would also not be a simple exercise and talented creditors' lawyers would no doubt press for an expansive view. [...] it is not always easy to determine whether a company even meets the test for solvency. Given that reality and the plaintiff friendly standard that applies to attacks on pleadings, it is not surprising that in the past there have been (and inferably in the future there will be) situations when creditors are accorded standing to assert fiduciary duty claims at the pleading-stage and when, after discovery, courts determine that the companies were not insolvent. [...]». 
tutelar los intereses de los acreedores. En una reciente sentencia ${ }^{37}$, sobre un caso muy complejo, se lee que una sociedad es insolvente ${ }^{38}$ cuando es incapaz de satisfacer sus obligaciones en un plazo regular o cuando presenta pasivos superiores al razonable valor de mercado del activo ("a corporation is insolvent when it is unable to pay its debts as they become due or when the corporation has liabilities in excess of the reasonable market value of its assets»), en cambio, está cerca de la insolvencia cuando es tan próxima la ruina que una persona razonable no puede negar que su capacidad de efectuar el pago se ve amenazada significativamente ("a corporation is in the zone of insolvency when the corporation is close enough to insolvency that a reasonable person would know that its ability to pay creditors in significantly threatened»). La imprecisión de la noción zone of insolvency, que se refiere a un criterio de razonabilidad del hombre medio, que se usa con dificultades para discernir las situaciones de crisis que necesitan la intervención de un procedimiento concursal de los que, en cambio, no lo imponen ni lo consienten, evidencia como la referencia a esta elaboración, si bien interesante, no puede facilitar la tarea interpretativa que aquí interesa. Por otra parte, una reciente y muy importante sentencia del Tribunal Supremo de Delaware ha encauzado la tendencia a conferir valor al concepto (impreciso) de zone of insolvency, al afirmar que, aunque concurre este estado, los administradores no tienen que cambiar la dirección de sus obligaciones fiduciarias, las cuales tienen que orientarse a la sociedad y a sus accionistas ${ }^{39}$. Dado que la noción de zone of

37 Wooley v. Lucksinger, 2008 WL 6457570 (So.2d) (La.App. 1 Cir., 2008).

38 La insolvencia tiene que ser entendida sea en le sentido patrimonial (incsolvency in equity sense), es decir cuando la empresa tiene un patrimonio insuficiente para cumplir con las obligaciones en plazo, sea de renta (insolvency in bankruptcy sense), cuando la empresa no es capaz de afrontar las obligaciones cuando éstas están en plazo.

39 Cfr. North American Catholic Educational Programming Foundation, Inc. v. Gheewalla, 930 A.2d 92, 101 (Del. 2007) (estableciendo que «when a solvent corporation is navigating in the zone of insolvency, the focus for Delaware directors does not change: directors must continue to discharge their fiduciary duties to the corporation and its shareholders by exercising their business judgment in the best interests of the corporation for the benefit of its shareholder owners»); de otra forma, en pasado, Geyer v. Ingersoll Pubs. Co., 621 A.2d 784, 791 (Del.Ch.1992); Credit Lyonnais Bank Nederland, N.V. v. Pathe Commc'ns Corp., Not Reported in A.2d, 1991 WL 277613 (Del.Ch. 1991), en 17 Del. J. Corp. L. 1099 (1991). Sobre el tema Douglas G. Baird, M. Todd Henderson, Other People's Money, en 60 Stan. L. Rev. 1309 (2008) (por la idea que las obligaciones fiduciarias se dirigen a los socios pero no deben ser utilizadas come ganzúa para poner los administradores en situaciones de incómodo objetivo en la conducción de la empresa), y más Rutheford B. Campbell, Jr. \& Christopher W. Frost, Managers' Fiduciary Duties in Financially Distressed Corporations: Chaos in Delaware (and Elsewhere), in 32 J. Corp. L. 491 (2007); Richard M. Cieri \& Michael J. Riela, Protecting Directors and Officers of Corporations That Are Insolvent or In the Zone or Vicinity of Insolvency: Important Considerations, Practical Solutions, in 2 DePaul Bus. \& Com. L.J. 295, 301-02 (2004); Patrick M. Jones \& Katherine Heid Harris, Chicken Little Was Wrong (Again): Perceived Trends in the Delaware Corporate Law of Fiduciary Duties and Standing in the Zone of Insolvency, in 16 J. Bankr. L. \& Prac. 2 (2007); Laura Lin, Shift of Fiduciary Duty Upon Corporate Insolvency: Proper Scope of Directors' Duty to Creditors, in 46 Vand. L.Rev. 1485, 1487 (1993); Jonathan C. Lipson, Directors' Duties to Creditors: Power Imbalance and the Financially 
insolvency no se utiliza para el acceso a los procedimientos, el Tribunal del Delaware la ha vaciado, en definitiva, de su único, posible contenido. En esta misma sentencia, por otra parte, se ponen de relieve los principios que la jurisprudencia ha elaborado para comprobar la insolvencia a los efectos del acceso a los procedimientos, bien de reorganización bien de liquidación; ésta subsiste cuando una empresa (es más, una sociedad), aun alternativamente, presenta: 1) una escasez del patrimonio con respecto al pasivo sin una razonable perspectiva de que la actividad pueda continuarse con éxito sin intervenciones ( 1 a deficiency of assets below liabilities with no reasonable prospect that the business can be successfully continued in the face thereof»), o 2) una incapacidad de satisfacer las obligaciones que se van devengando en el curso normal de la actividad de la empresa («an inability to meet maturing obligations as they fall due in the ordinary course of business $\rangle)^{40}$.

La noción americana de insolvency, por supuesto, no es muy diversa que la que expresa el art. 5 de la ley de quiebras. Ya que en los Estados Unidos el acceso a un procedimiento reorganizativo o liquidativo se basa en el mismo presupuesto (insolvency) y, para los de carácter preventivo - que, de hecho, son bastante precoces y eficaces - no se sirve de la zone of insolvency, se caería en la tentación de devaluar la distinción entre insolvencia y crisis, ampliada la noción de la primera de modo que se cubra enteramente el sentido de la segunda.

Éste es, de hecho, el núcleo de la tesis propuesta por una autorizada parte de la doctrina en Italia, que niega la distinción entre el estado de crisis e insolvencia

Distressed Corporation, in 50 UCLA L.Rev. 1189 (2003); Ramesh K.S. Rao, et al., Fiduciary Duty A La Lyonnais: An Economic Perspective on Corporate Governance in a Financially-Distressed Firm, in 22 J. Corp. L. 53 (1996); Myron M. Sheinfeld \& Harris Pippitt, Fiduciary Duties of Directors of a Corporation in the vicinity of Insolvency and After Initiation of a Bankruptcy Case, in 60 Bus. Law. 79 (2004); Robert K. Sahyan, Note, The Myth of the Zone of Insolvency: Production Resources Group v. NCG Group, in 3 Hastings Bus. L.J. 181 (2006); Vladimir Jelisavcic, Corporate Law-A Safe Harbor Proposal to Define the Limits of Directors' Fiduciary Duty to Creditors in the «Vicinity of Insolvency:» Credit Lyonnais Bank Nederland N.V. v. Pathe Commc'ns Corp., in 18 J. Corp. L. 145 (1993); Stephen M. Bainbridge, Much Ado About Little? Directors' Fiduciary Duties in the Vicinity of Insolvency, in 1 J .Bus. \& Tech. L. 335 (2007); J. William Callison, Why a Fiduciary Duty Shift to Creditors of Insolvent Business Entities Is Incorrect as a Matter of Theory and Practice, in 1 J. Bus. \& Tech. L. 431 (2007); Larry E. Ribstein \& Kelli A. Alces, Directors' Duties in Failing Firms, in 1 J. Bus. \& Tech. L. 529 (2007); Frederick Tung, Gap Filling in the Zone of Insolvency, in 1 J. Bus. \& Tech. L. 607 (2007). Por último, para hacer una lectura comparatística, Justin Wood, Director Duties and Creditor Protections in the Zone of Insolvency: A Comparison of the United States, Germany, and Japan, in 26 Penn. St. Int'1 L. Rev. 139 (2009).

40 Noción que afecta a Production Res. Group v. NCT Group, Inc., 863 A.2d 772, 782 (Del.Ch.2004), citando Siple v. S \& K Plumbing \& Heating, Inc., 1982 WL 8789, at *2 (Del.Ch. Apr. 13, 1982); Geyer v. Ingersoll Publ'ns Co., 621 A.2d 784, 789 (Del.Ch.1992) (donde por primera vez aparece el concepto de que una sociedad es insolvente cuando «it has liabilities in excess of a reasonable market value of assets held»); y la remota McDonald v. Williams, 174 U.S. 397, 403, 19 S.Ct. 743, 43 L.Ed. 1022 (1899) (donde por la primera vez aparece la noción de sociedad insolvente como «an entity with assets valued at less than its debts»). 
considerada con el método perspectivo ${ }^{41}$. Sin embargo, esta propuesta parece contrastar con un dato normativo que no conviene pasar por alto. Antes que nada, debe observarse que sólo a falta de una noción de crisis diversa, que incluya la insolvencia, podía ser legítimo hacer tan elástica la segunda noción de modo que cubra enteramente el área hoy ocupada por la primera. Si se teme una posible "expropiación" de los acreedores contrarios, por otra parte: ¿Se acaba con conceder al juez un poder de revalorización sobre la subsistencia de los presupuestos, que no resulta compatible con la exigencia de una posibilidad de acceso más fácil al procedimiento, posibilidad de la que se reconoce mayoritariamente su necesidad y oportunidad?. Ateniéndose a los datos legislativos, pues, es importante encontrar y aplicar una distinción coherente donde sólo la insolvencia es el presupuesto del procedimiento y donde, en cambio, es suficiente la crisis: la noción de crisis debe orientarse a favor de un acceso fácil y precoz al procedimiento, pero sin resultar vaciada del todo. De lo contrario, habría sido suficiente remitir al simple acuerdo entre la mayoría de los acreedores y deudor la aprobación del plan de saneamiento, sin la remisión a la crisis ${ }^{42}$. Está claro que el solo acuerdo no es suficiente para el convenio - aunque puede ponerse en duda para los acuerdos de reestructuración ${ }^{43}$ - precisamente porque la posibilidad de producir efectos jurídicos en los acreedores

41 Extensamente G. TERRANOVA, Stato dicrisi, cit., pp. 15 y ss., spec. 40 y ss.; y además D. GALLETTI, ob. cit., pp. 2274 y ss. (y ya ID., La ripartizione del rischio di insolvenza, Il Mulino, Bolonia, 2006, pp. 157 y ss.) para la observación de que «no hace falta hablar de riesgo o peligro de insolvencia». La tesis, en cierto modo, es avalada por una reciente sentencia del Tribunal de Casación, que comparando el presupuesto para el acceso al superado procedimiento de administración controlada (dificultad temporal) y el de la liquidación forzosa administrativa (insolvencia) ha considerado la identidad ontológica, al precisar que el primero es diferente «de este último sólo en cuanto, en el primer procedimiento, subsiste el probable carácter reversible de la situación de insolvencia; por lo tanto, si la empresa puesta en administración controlada sucesivamente se somete a una liquidación forzosa administrativa, se debe considerar probada el carácter irreversible del estado de insolvencia, ya que el segundo procedimiento se dirige a la liquidación de la empresa y, por lo tanto, es incompatible con la posibilidad del saneamiento de la empresa [...]». Así, Casación, 9 de septiembre 2005, n. 18066, en Giust. Civ., 2006, I, 546.

42 Sobre el punto v. R. MANGANO, Linsolvenza nell'esperienza tedesca, en G. Terranova, Stato di crisi e stato di insolvenza, cit., pp. 109 (que considera que ello, en definitiva, es el resultado que se ha logrado con la codificación del $\S 18$ Ins $O$ en Alemania, donde con una formulación de «molde marcadamente americano» se permite «al deudor la activación del procedimiento, es decir, ad natum, o sea, prescindiendo de la existencia de una condición de crisis»).

43 Se puede dudar - y yo dudo - de que sea oportuno confiar al juez de la homologación de un acuerdo de reestructuración el poder de fiscalizar la existencia del estado de crisis. De hecho, me parece que el acreedor ajeno al acuerdo tiene interés solo en recibir un pago integral y puntual, con las garantías conexas. Si falta la crisis es del todo improbable - si no imposible - que el mismo pueda sufrir un prejuicio. 
que no consienten se basa en un problema común (llamado common pool problem) ${ }^{44}$ - la crisis - cuya solución se somete a la mayoría por el carácter instrumental de los intereses entre todos los componentes del grupo (llamado Interessengemeinschaft) ${ }^{45}$. Si no hay crisis, tampoco hay una comunidad de intereses convergentes y no tiene sentido asignar a la mayoría el poder de decidir sobre la adhesión o no a la propuesta.

\section{Solución de la crisis y reestructuración de la deuda.}

Desde el punto de vista de una distinción entre crisis e insolvencia, que es conveniente, resulta eficaz la idea de que se pasa a la segunda cuando el empresario en crisis ya no es capaz de instar ni siquiera inversiones de riesgo, resultando «rechazado por el mercado financiero» ${ }^{46}$. La idea, sin duda, da en el blanco. Para facilitar la tarea del intérprete que tiene que medirse con las normas del ordenamiento positivo, que se refieren en diversos contextos y con una relación de continencia entre crisis e insolvencia, es necesario desarrollarla pues es más pertinente al dato normativo. En

44 Sobre la noción del common pool v. Alan E. Friedman, The Economics of the Common Pool: Property Rights and Exhaustible Resources, in 18 UCLA L. Rev. 855 (1971) y más recientemente, en sentido crítico, Eric A. Posner, Law, Economics, and Inefficient Norms, in 144 U. Pa. L. Rev. 1697, a pp. 1740 e seg. (1996) (considerando que «the literature has not produced a clean resolution and now consists of efforts to identify the conditions under which common-pool problems are solved. The efficient-norm view predicts that common pools are governed by efficient norms when (1) only a close-knit group has access to the common pool; (2) the state enforces underlying property rights; and (3) endowments are relatively equal»). La teoría del common pool problem es empleada en materia de bankruptcy por Thomas H. JACKSON, The Logic and Limits of Bankruptcy Law, Harvard University Press, Cambridge Mass., 1986, 7 11, el más acreditado estudioso americano de Derecho de quiebra (y por el mismo autor se veanse también Bankruptcy, Non-Bankruptcy, Entitlements, and the Creditors' Bargain, in 91 Yale L.J. 857 (1982); Of Liquidation, Continuation, and Delay: An Analysis of Bankruptcy Policy and Nonbankruptcy Rules, in 60 Am. Bankr. L.J. 399 (1986)). Más recientemente, entre muchos, v. James W. Bowers, Groping and Coping in the Shadow of Murphy's Law: Bankruptcy Theory and the Elementary Economics of Failure, en 88 Mich. L. Rev. 2097 (1990); Susan Block-Lieb, Fishing in Muddy Waters: Clarifying the Common Pool Analogy as Applied to the Standard for Commencement of a Bankruptcy Case, in 42 Am. U. L. Rev. 337 (1993) (y después The Logic and Limits of Contract Bankruptcy, en U. Ill. L. Rev. 503 (2001)); Barry E. Adler, Financial and Political Theories of American Corporate Bankruptcy, en 45 Stan. L. Rev. 311 (1993); Donald R. Korobkin, Rehabilitating Values: A Jurisprudence of Bankruptcy, en 91 Colum. L. Rev. 717 (1991) (y después Contractarianism and the Normative Foundations of Bankruptcy Law, en 71 Tex. L. Rev. 541 (1993)); Richard V. Butler, Scott M. Gilpatric, A Reexamination of the Purposes and Goals of Bankruptcy, en 2 Am. Bankr. Inst. L. Rev. 269 (1994).

45 El tema del carácter instrumental de los intereses entre acreedores en el convenio preventivo había sido estudiado, antes de la reforma, por R. SACCHI, Il principio di maggioranza nel concordato preventivo e nell'amministrazione controllata, Giuffrè, Milán, 1984, pp. 240; que ha retornado sobre el tema, a la luz de la reforma y desde una diversa perspectiva, en Concordato preventivo, conflitti di interesse tra creditori e sindicato dell'autorità giudiziaria, en Fall., 2009 (Anexo 1/2009), 30. el tema se desarrolla extensamente, en clave negocial, por G. NUZZO, Poteri del tribunale nel concordato preventivo, cit., pp. 35 y ss.

46 L. STANGHELLINI, La crisi dell'impresa tra diritto ed economia, cit., pp. 123-125. 
este sentido, con insolvencia se puede entender la situación en la cual el empresario, a falta de nuevas inversiones a riesgo, propias o de terceros - o, por lo menos, de un aumento de valor de los efectuadas, si son suficientes - no es capaz de asegurar el regular pago de las deudas contraídas o a plazo ${ }^{47}$, mientras que con crisis se indica, también, una dificultad que puede ser superada con la simple reestructuración de la deuda. A esta formulación - que dentro de poco será aclarada en cuanto a las consecuencias de su aplicación - se dirige un elemento contenido en el art. 160, conma 1, letra $a$ ), ley de quiebras, en el que se consideran, como contenido del plan idóneo a la superación de la crisis y desde el punto de vista de continuidad de la empresa, intervenciones exclusivamente del lado del pasivo, sin nuevas inversiones; es decir, la reestructuración de las deudas y la satisfacción de los créditos con cualquier medio. Éstos son remedios aptos para la superación de una crisis que no ha erosionado los valores empresariales hasta tal punto de requerir imprescindiblemente nuevos recursos de riesgo para que la actividad de la empresa pueda seguir, aunque con un programa reducido. La norma, importada de la experiencia de la administración extraordinaria (de las grandes empresas insolventes), pero introducida de forma más adecuada en el contexto de empresas en crisis, parece constatar la necesidad de consentir el acceso a los procedimientos de saneamiento de la empresa desde el momento en que ello puede ocurrir sin el recurso a nuevo capital de riesgo, al actuar exclusivamente en el pasivo. Pasivo que del que puede modificarse la determinación en cuanto a los plazos (por ejemplo a través la emisión de obligaciones o títulos de deuda) o que puede ser transformado en capital (con la asignación a los acreedores de unas acciones o cuotas de la sociedad saneada a nivel financiero). En este sentido, se puede decir que la empresa es insolvente si a la reestructuración del pasivo necesariamente debe acompañar la inyección de una nuevos recursos de riesgo (y por tanto, en su defecto, debe quebrar y ser liquidada), mientras que es meramente en crisis cuando la intervención en el frente del pasivo es aún posible. A partir de esta idea de fondo puede ser útil una individuación más analítica de algunas graduaciones de la crisis y de la insolvencia, algunas meramente descriptivas, otras en cambio útiles para identificar los umbrales de acceso a los procedimientos. Partimos de la crisis más grave y mejor explorada en literatura, es decir, de la insolvencia. Como se ha indicado, según una eficaz definición pretoria (del juez de primera instancia), la insolvencia es una situación (que se refiere a una empresa) de impotencia económica funcional no transitoria. Es irreversible cuando cualquier inversión no permita la recuperación del equilibrio económico y financiero de la empresa (lo que conduce al

$47 \quad$ Al respecto, el legislador español distingue entre insolvencia (actual) e insolvencia inminente conectando la primera a la incapacidad de cumplir regularmente con las obligaciones «exigibles», y la segunda a la incapacidad de cumplir regular y puntualmente con las obligaciones aunque no estén vencidas. Art. 2.2 y 2.3 Ley concursal. Advierte A. RoJo, op. cit., p. 167, de que mientras el procedimiento concursual se activa/abre a iniciativa del deudor cuando la insolvencia es actual o inminente, los acreedores deben indicar la subsistencia de uno de los factores que revelan la insolvencia para obtener la abertura del concurso (insolvencia cualificada). 
«rechazo del mercado financiero») y reversible cuando, en cambio, como se reconoce en la administración extraordinaria, este objetivo puede ser conseguido, a medio o hasta a corto plazo, a través de nuevas inversiones (de riesgo). En otras palabras, es irreversible la insolvencia de una actividad que no es capaz de producir, ni siquiera a la largo plazo, una renta adecuada para sostener el coste de las inversiones, que, por tanto, resultarían no solo irrecuperables (el llamado sunk cost), sino improductivas ${ }^{48}$. Reversible, la que, en cambio, permite el reajuste de los asientos del coste a los de renta (llamada breakeven), a través una inversión desde un punto de vista remunerativo. Puesto que no pueden ser planteadas inversiones, ni a los «propietarios» de la empresa insolvente ni a sus acreedores, ni puede ser recuperada la economicidad de la empresa actuando solo en el frente de la deuda, el carácter reversible del estado de insolvencia no impide, y es más determina, el acceso a un procedimiento concursual liquidatorio.

La insolvencia, normalmente, se revela con la incapacidad patrimonial, es decir, con la erosión integral del patrimonio de riesgo y, cancelado el colchón protector de los propios medios, de cuotas más o menos consistentes de los adquiridos a través la deuda. Sin embargo, para que haya la insolvencia - que es una situación esencialmente de renta, no patrimonial ${ }^{49}$ - la incapacidad no es esencial. De insolvencia, de hecho, es lícito hablar aún cuando el patrimonio es suficiente pero carece de liquidez ${ }^{50}$, o sea, que a partir del mismo no se logra generar una renta que permita efectuar, a su vencimiento, los pagos que implica la actividad de la empresa.

48 Los costes irrecuperables (o: ¿Costes hundidos profundos?) son los que no pueden ser recuperados en ningún modo significativo: no se identífican con los costes fijos, contrapuestos a los costes variables, aunque a menudo forman parte de ellos. En la teoría microeconómica sólo los costes variables deben influir en una decisión de inversión. La insolvencia irreversible, pues, es una situación económica en que no son recuperables ni siquiera los costes variables y la empresa, en vez de producir, gasta.

49 Este es un punto pacífico en la literatura más reciente, pero no lo era en el pasado: y v. por todos G. TERRANOVA, La nozione di insolvenza, cit., p. 95 (observa que «la insolvencia no es un mero hecho, y ni siquiera un estado patrimonial, sino una incapacidad del subjeto de mantener una determinada conducta prolongada en el tiempo»). Resulta muy eficaz la acentuación por A. Rojo, op. cit., p. 169 para el cual el deudor no «es» sino «está» insolvente (distinción intraducible al italiano), subrayando con ello una condición con «cierto grado de continuidad. Para que exista insolvencia se requiere continuidad de la imposibilidad».

50 La condición de la falta de liquidez no es una simple deficiencia de la caja, que al más puede determinar un retraso y, por tanto, un coste en intereses, sino una incapacidad estructural de efectuar pagos en moneda (análogamente, referiéndose al estado de insolvencia inminente en el ordenamiento español, A. Rojo, op. cit., p. 176 «no se trata de que el deudor prevea que en un determinado momento se va a encontrar con dificultades transitorias de tesorería [...]»). Parece particularmente significativo al respecto lo que observa la Apelación Génova, 28 de abril de 2004, en Dir. Fall., 2005, II, 99, según la cual «la insolvencia, en otras palabras, es una situación objetiva y transitoria de falta de liquidez y no de imposibilidad, siendo, pues, suficiente para examinar su existencia que la realización, o mejor la liquidación, del activo, aunque existente en abstracto, como en el caso de un inmueble, no puede conseguirse fácilmente, en cuanto no puede hacerse con rapidez y sin pérdidas ruinosas». 
En este caso, el empresario que desarrolla la actividad sin revalorizar la inversión patrimonial, determina desde este punto de vista la erosión o anulación y puede ser declarado quebrado ${ }^{51}$. En general, hay insolvencia (perspéctica o pronóstica) ${ }^{52}$ cuando la continuación de la actividad de la empresa, sin una intervención idónea para aumentar la rentabilidad de la empresa, presagia no sólo el riesgo de pérdida integral del capital invertido, sino también el de incumplimiento de las obligaciones ya asumidas. En estos casos, es la perspectiva de la continuación de la empresa la que exige la intervención del procedimiento concursual, no declarando la quiebra de una empresa cerrada - y en particular, por consolidada jurisprudencia, de una sociedad en liquidación ${ }^{53}$ - sino en caso de incapacidad patrimonial. Delimitada el área de la insolvencia - área en que el acceso al convenio preventivo, liquidatorio o reorganizativo, no puede obstruirse - nos queda indicar cuándo aparece una crisis sin insolvencia. ¿A partir de la noción de insolvencia pronóstica/prevista? a la que se ha hecho ahora referencia, parece lícito hablar de crisis, separada de la insolvencia, cuando el coste de cumplir las obligaciones ya asumidas conduce a la incapacidad de los recursos necesarios para continuar la actividad de la empresa, incluso sin tener un riesgo inmediato de incumplimiento. En otros términos, se puede creer - y esta es mi propuesta - que no hay insolvencia, sino sólo crisis cuando, no obstante la «capacidad patrimonial», aparece la perspectiva de un agotamiento del patrimonio productivo, que pueda conducir a la incapacidad (de renta) de hacer frente no a las obligaciones ya contraídas, sino a las que implicará la continuación de la empresa.

En torno a esta cuestión, una parte de la doctrina se orienta decididamente a negar que la pérdida de rentabilidad sea suficiente para el acceso al concordato

51 Un ejemplo puede ilustrar con facilidad lo que se afirma en el texto. Supóngase que el propietario de un inmueble destinado a un uso relacionado con la hostelería incurre en constantes gastos de gestión que no se sostienen por los beneficios, ya que el inmueble está en malas condiciones y la clientela no lo elige. La exposición deudora del empresario hacia sus dependientes y suministradores puede ser encubierta ampliamente por el valor intrínseco del inmueble, pero esto no excluye que el mismo esté en estado de insolvencia si no «revaloriza» a través nuevas inversiones (también con el recurso al crédito) el complejo empresarial, llevándolo a condiciones de eficiencia productiva.

52 El punto se trata con particular claridad por G. TERRANOVA, La nozione di insolvenza, cit., pp. 117 y ss.

53 Cuando una empresa procede a la rescisión voluntaria, la insolvencia no puede ser considerada en términos de una perspectiva/prevista? incapacidad de pagos regulares, debiéndose asegurar exclusivamente en términos de capacidad patrimonial: v. por último Casación, 6 de septiembre de 2006, n. 19141, en Foro.it., 2007, I, 1531, con nota de M. FABIANI, observando que «en la empresa en liquidación, ya que el único objetivo es el de satisfacer las razones de los acreedores, el estado de insolvencia debe averiguarse con referencia al desequilibrio entre activo y pasivo, no más; revelando la capacidad de la empresa de quedarse en el mercado». Análogamente Casación, 17 de abril de 2003, n. 6170, en Foro.it, 2003, I, 2389, observando que cuando la empresa está en liquidación «si el activo puede asegurar el pago de manera igual y total de los acreedores no es necesario abrir el procedimiento concursual». Sobre la quiebra de las empresas extinguidas y para apuntes sobre a las en liquidación, v. por último M. SPERANZIN, Il fallimento delle società estinte, en Temas del nuevo derecho de quiebra, cit., pp. 129 y ss. 
preventivo $^{54}$. La postura no debe criticarse, sino articularse mejor. De hecho, parece intolerable la idea de que un empresario mantenga la reducida rentabilidad de la empresa - determinada por cualquier causa, hasta su incapacidad - y obtener un «descuento» de los acreedores, sobre todo, si lo obtiene al ejercer una (indebida) presión económica sobre ellos y se puede limitar a hablar con la mayoría. Pero éste no puede considerarse el único punto de vista. Es más, si se utiliza correctamente, llenándola de contenido, no resulta incómodo excluir las soluciones acordadas por la mayoría que no tienen en la crisis y, por tanto, en el carácter instrumental de intereses entre empresario y acreedores, su razón de ser. En efecto, puesto que no puede ser defectuoso el presupuesto de una «crisis» cuya solución es en el interés común del empresario y de los acreedores, me parece que no puede obstruirse el recurso al concordato preventivo en situaciones que socavan con anterioridad las relaciones entre empresario y su acreedores, aunque no hagan aflorar una incapacidad actual de hacer frente regularmente a las obligaciones ya asumidas. El recurso al concordato preventivo también en estos casos puede estar perfectamente justificado. Cuando la programación de la actividad de la empresa a medio plazo denota la necesidad de una recapitulación, puede ser razonable consentir el acceso a un procedimiento que tiene como objetivo el de repartir el coste de la reestructuración entre acreedores actuales y socios, sobre todo, donde el fin compartido por ambos es el de asegurar una continuidad a las relaciones jurídicas. Para dar un ejemplo que puede percibirse fácilmente, una empresa podría pensar en el concordato preventivo para negociar con los propios empleados una reducción del salario que se ha devengado o se devengue para mantener, de cara al futuro, el nivel ocupacional o salarial, ofrecer, a cambio, perder solo una parte de la inversión, o una parte inferior, sin restablecer la pérdida. Precisamente, sería la solución de una «crisis» a través una reestructuración llevada a cabo exclusivamente en el frente de la deuda. Un razonamiento análogo puede valer para los acreedores que tienen interés en continuar las relaciones (piénsese en todas las empresas con unas fuertes actividades económicas derivadas) que también podrían consentir una conversión de la deuda en capital.

En definitiva, si se aprovecha la definición del presupuesto para la admisión al concordato preventivo objeto de reforma para favorecer un acceso anticipado a los procedimientos alternativos con respecto a la quiebra, la interpretación de esta noción debe ser tal que no se impida al empresario proponer un plan de saneamiento y no se impida a los acreedores aprobar o no en mayoría, al valorar la conveniencia da la operación. De lo anterior sigue que, al volver a las interrogantes que se ponen de relieve más adelante, debe o debería considerarse crisis a los efectos de un procedimiento concursual, o extrajudicial con efectos concursuales, también la que puede superarse sin acuerdos con los acreedores, sino recorriendo a nuevos recursos, o la que manifiesta una dificultad de mantenimiento de la cuota de mercado peligrosa

54 L. GUGLIELMUCCI, Diritto fallimentare, cit., p. 314 y ya, en la literatura económica, GUATRI, Crisi e risanamento dell'impresa, cit., pp. 106 y ss. 
en perspectiva para la conservación de la empresa. Por el contrario, es legítimo aceptar la instancia de los acreedores que contestan la falta de las condiciones por el procedimiento cuando resulta que la empresa no arriesga ni siquiera en perspectiva agotar los recursos necesarios para continuar. Si esta comprobación es fácil, no se puede decir; pero es mejor un convenio de más que una quiebra de más.

\section{Ne eat iudex ultra petita (...) es decir, la evaluación de la crisis durante la admisión.}

La última observación del párrafo anterior, somete a examen otro aspecto crítico del problema que afecta a la admisión al concordato preventivo: o sea, la necesidad de determinar sobre quién pesa la carga de demostrar la existencia de las condiciones para el acceso al procedimiento y en qué términos se pueden investigar.

De hecho, resulta evidente cuánto puede influir este aspecto sobre la rapidez del procedimiento y sobre su eficacia y, por lo tanto, puede resultar determinante sobre el bajo dato estadístico registrado. En efecto, puesto que la demanda corresponde sólo al deudor, éste declara el estado de crisis con la propuesta de acuerdo ${ }^{55}$. La ley no pide al declarante probar lo que afirma ${ }^{56}$. La existencia de la crisis, a lo sumo, tendrá que revelarse de la relación sobre el estado activo y pasivo, financiero y sobre la situación económica, y tendrá que depositarse junto al recurso y al plan. El experto tiene que atestiguar la veracidad de los hechos empresariales y el carácter factible del plan pero sin confirmar la existencia de la crisis $^{57}$.

Dicho esto, ya que la declaración del estado de crisis o su admisión implícita no es favorable al deudor, no es ilógico suponer que en realidad existe un estado de $\mathrm{crisis}^{58}$, siempre y cuando no se demuestre lo contrario en la documentación preparada por él mismo (ésta solución ha sido adoptada de forma pacífica en España) ${ }^{59}$ o hasta que los acreedores interesados no la niegan, se oponen y explican al juez las razones por

55 En sentido similar, en relación con la dificultad momentánea, Tribunal Udine, 20 de octubre de 1997, en esta Revista, 1997, II, 1245, observando que la sociedad que solicite ser admitida al procedimiento de suspensión de pagos, admite que se encuentra en un estado de quiebra ya que insolvencia y dificultad temporal son dos gradaciones del mismo fenómeno económico.

56 Sobre la prueba de la insolvencia por la declaración de quiebra, v. ultra nt. 66.

57 Veer sobre este argumento G. VERNA, La relazione professionale che accompagna il piano di concordato preventivo, en Dir. Fall., 2008, I, 231.

58 No es de la misma opinión G. Terranova, Stato di crisi, cit., p.27.

59 El legislador español asigna una diferente carga probatoria según la solicitud de apertura del concurso haya sido presentada por el deudor o por los acreedores: el primero tiene que probar la deuda y la insolvencia actual o inminente; los acreedores tienen que demostrar la falta de cumplimiento o incapacidad patrimonial, o sea, algunos hechos específicos que revelan la crisis (insolvencia cualificada). Sobre esta cuestión, A. Rojo, op. cit., pp. 173 y ss., quien precisa que la solicitud del deudor ya resulta bastante idónea para el reconocimiento objetivo del estado de insolvencia, sin perjuicio de que el juez tiene el poder de revisar la existencia del estado por cuenta de terceros, es decir, sobre todo de los acreedores. El mismo autor es claro cuando afirma que la ley «no exige que [...]. Justificar...acto». ID., a la p. 174. Por lo que respecta la insolvencia inminente, que permite sólo al deudor solicitar la apertura del concurso, se observa que: «la prueba (...) real». ID., a la p. 177. 
las que temen que un acuerdo aprobado, a pesar del proprio voto contrario, pueda perjudicarlos ${ }^{60}$. Esta es, por lo demás, la solución americana en caso de voluntary filing, es decir de acceso al procedimiento por iniciativa del deudor ${ }^{61}$ : procedimiento de gran éxito bien para las empresas menores, bien para las de dimensiones notables ${ }^{62}$.

Sobre este tema, algunos tribunales ofrecen un legado de desconfianza que debe superarse. No se puede ignorar, en efecto que mientras como regla, por lo menos en el pasado, se ha demostrado el recurso de manera importante a las quiebras oportunistas (se habla nada menos que de "profesionales" de la quiebra) ${ }^{63}$, no resulta evidente el empleo con carácter instrumental del concordato preventivo, fundamentalmente porque el mismo necesita de la aprobación de los acreedores. Ni se puede sobrestimar el hecho de que la presentación de la demanda de concordato preventivo se pueda instrumentalizar para retrasar la declaración de quiebra: es evidente que si el empresario intenta retrasar la quiebra, la existencia de la crisis no admite discusión. El concordato está siempre sujeto a anulación cuando se puede probar que el pasivo ha sido intencionalmente exagerado o bien sustraido o disimulado parte relevante del activo (así el art. 138 al que reenvía el art. 186 ley de quiebras). Por lo tanto, se puede compartir la propuesta de quien ${ }^{64}$, sin excluir que el tribunal tiene el poder de averiguar la subsistencia de la crisis durante la admisión, sin embargo, juzga inoportuno un examen extra-documental ex officio iudicis. Entre los deberes del comisario judicial se encuentra la redacción de una relación pormenorizada sobre las causas del fracaso y sobre la conducta del deudor; la relación del comisario permite al juez además volver a examinar el juicio formulado durante la admisión (y en concreto revocar la medida de admisión) a pesar del voto favorable de la mayoría de los acreedores y también a falta de oposiciones (art. 173 ley de quiebras). Esta solución aparece eficiente y sustancialmente respetuosa con la letra de la ley. Aunque los jueces llevan a cabo un control solo documental durante la admisión, los mismos no violan la disposición del

60 En sentido análogo, sin embargo, con referencia a la disciplina derogada, A. Bonsignori, Del concordato preventivo, en Comentario Scialoja-Branca. Ley de quiebra, a cura de Bricola, Galgano y Santini, Zanichelli, Bologna-Roma, 1979, sub art. 162, p. 16, quien cree que de la demanda de concordato se puede deducir una presunción o (argumento de prueba) bien del estato de insolvencia, bien de la condición de empresario comercial.

61 En caso de que el procedimiento se abra con la solicitud presentada por el mismo deudor, la emisión del order for relief es automatica (Bankruptcy code, § 1121). La valoración de mérito acerca de la subsistencia del estado de insolvencia, en cambio, se activa en caso de que el procedimiento se abra con una istancia presentada por un acreedor (involuntary case): el juez, en efecto, no puede declarar la quiebra si el deudor niega al acreedor solicitante que el mismo ha sido pagado a plazos (equity insolvency) ( $\$ 303 \mathrm{~h}$ Bankruptcy code).

62 Basta con recordar las admisiones de los grandes constructores de automóviles y de los bancos del último año, de General Motors a Chrysler, de Wachovia a Lehman Bros. - que ha recurrido igualmente a un procedimiento de reorganization ex Chapter 11 aunque se usa para efectuar una liquidación - y de muchas compañías aéreas en un pasado reciente, de Delta a United que se han salvado, hasta Pan Am y TWA que han sido liquidadas, la primera, o cedidas y absorvidas, la segunda.

63 V. L. Stanghellini, Le crisi di impresa fra diritto ed economia, cit. Pp. 138-40.

64 G. Nuzzo, I poteri del tribunale nel concordato preventivo, cit., pp. 63 e ss.. 
art. 162 ley de quiebras, porque la ley no requiere practicar investigaciones sobre la subsistencia de los presupuestos del procedimiento (i.e., estado de "crisis" y status de empresario comercial sujeto a los procedimientos de la quiebra y del concordato preventivo, ex art. 1 ley de quiebras) ${ }^{65}$, sino sobre los presupuestos para la admisión al procedimiento (es decir, que el sedicente empresario en crisis haya presentado un plan debidamente formulado, dotado de las alegaciones necesarias e introducido a través de un recurso regular, ex arts. 160 , incisos $1^{\circ}$ y $2^{\circ}$, y 161 ley de quiebras).

El legislador, por otra parte, ha precisado que se trata de presupuestos y no de condiciones (d. lgs. 167/07). Así como se ha estructurado el acceso al procedimiento de concordato preventivo, los acreedores no tienen manera de avanzar sus solicitudes durante la admisión y el perjuicio que puede derivarse para ellos de la admisión del procedimiento es sólo el de no poder empezar o continuar acciones individuales hasta el momento en que se requiera una comprobación sobre la subsistencia de los presupuestos del procedimiento. Se trata de una verificación que pueden solicitar de inmediato a causa de su convocatoria para la aprobación del concordato y en cualquier momento del procedimiento (ex art. 173, inciso $3^{\circ}$, ley de quiebras).

Las garantías en defensa de los acreedores, pues, no faltan. La ventaja de esta lectura es que un control de regularidad solo documental puede contribuir significativamente a la rapidez del procedimiento en sus primeras fases: y esto es, si se comparte cuánto se ha dicho antes, lo que puede hacer apeticible el procedimiento concordatario y favorecer un empleo más amplio. De lege lata, sería, pues, deseable que los jueces acepten durante la admisión al concordato preventivo, la erosión de los poderes también de oficio que justa y oportunamente ejercen durante la comprobación del estado de insolvencia a la vista de la declaración de quiebra (con un procedimiento sumario más profundo del que puede haber durante el concordato) ${ }^{(66)}$, con la conciencia de que este retroceso favorece la eficiencia del sistema sin comportar riesgos significativos.

65 Conforme, G. SAntoni, en Le soluzioni concordate delle crisi d'impresa, cit., p. 52.

66 Es un punto pacífico en jurisprudencia que durante la oposición a la sentencia declarativa de quiebra, la aplicación del principio general sobre la carga de las partes de proveer la prueba de las correspondientes alegaciones, no excluye el poder-deber del juez de hallar, también de oficio, la subsistencia del estado de insolvencia y de cada uno de los demás presupuestos de la misma quiebra (por tanto, también la condición de empresario comercial "falible"). Así, Cassazione, sez. I, 20 de agosto de 2004, n. 16356, en Fall., 2005, 743; Cassazione, 28 de junio de 1985, n. 3877, en Giur. it., 1986, I, 1, 409; Appello Cagliari-Sassari, 23 de julio de 1998, en Rev. giur. sarda, 2000, 363. Es sabido que la cuestión de los requisitos de falibilidad es actual en relación al novellato art. 1 ley de quiebra con una sanción significativa del Tribunal Torino 11 de jenero de 2007, en Fall., 2007, 319, con nota de M. Fabiani; in Giur. piemontese, 2007, 90; in Giur. it., 2007, 2223, con nota de M. IRRERA e ivi 2271, con nota de CANALE, donde se ha afirmado que el título de empresario no pequeño, para las sociedades comerciales, tiene que suponerse porque se trata de una connotación natural de la tipología social; la eventual fallida superación de los límites previstos por el art. 1 ley de quiebras tiene que ser probada y alegada por la parte interesada [...]. Esta solución la ha hecho propia en lo sustancial el legislador que, con el decreto correctivo n. 169/2007, ha precisado que los requisitos, art. 1, inciso 2, ley de quiebras, tiene que demostrarlos el empresario. Esta aclaración, a mi parecer, no atañe ni a la insolvencia (que puede ser verificada de oficio si las partes no han provisto pruebas suficientes) ni al estado de crisis tratado en el texto. 


\section{Cómo «curar» el concordato preventivo, de lege lata: propuestas sobre el acceso al procedimiento y sobre la formulación del plan.}

La iniciativa con respecto al concordato corresponde exclusivamente al deudor. En los concordatos que han sido introducidos en un procedimiento ya activo, (concordato fallimentare y concordato en la administración extraordinaria común), la iniciativa corresponde, en cambio, aunque en tiempos diferentes, tanto al deudor como a los acreedores y a terceros. En la administración extraordinaria especial, por último, la propuesta corresponde exclusivamente al comisario con la autorización del Ministerio de las Actividades Productivas. El poder de iniciativa para la propuesta del concordato es un factor indudablemente relevante para la eficacia del procedimiento. Se trata, no obstante, de aspectos regulados por la ley sobre los que poco o nada puede influir la interpretación académica y donde la regla puede tener escaso margen de maniobra, aunque esté apoyada por la jurisprudencia.

Esta parte del análisis tiene el objetivo de poner en tela de juicio la disciplina existente y de formular propuestas para su superación.

Sería en principio eficiente asignar la iniciativa de una activitad a la parte que tiene mayor interés en conseguir los resultados que a la misma están conectados. Pero no es igualmente eficaz. Para inducir a una parte a tomar una iniciativa - aunque abstractamente en interés de todo un grupo - el temor de las consecuencias negativas que, en su defecto, se pueden derivar (deterrence). También intuitivamente se induce al comportamiento humano más fácilmente a mejorar una situación presente mediante un incentivo ${ }^{67}$ que con el riesgo de empeorarla, puesto que el riesgo es por su naturaleza desconocido ${ }^{68}$. Cabe destacar que no parece que los empresarios italianos vean una ventaja en el acceso al concordato con respecto de la continuación de negociaciones llevadas privadamente con algunos acreedores o hasta nada menos que con todos. Es más bien verosímil que la proposición del concordato sea vista como una disminución/aminoración de la capacidad de conducir la negociación bien porque el empresario tendrá también que relacionarse con los órganos judiciales, bien, sobre todo, porque en el momento en que se presenta la demanda de admisión el empresario tiene que someter el plan para cristalizar, pues, el estadio de las negociaciones. La situación que se presenta ante la presencia del empresario en crisis aparece caracterizada por el riesgo de empeorar solamente. Es un dato de la

67 Sobre el uso de los incentivos como estrategias en modo de premios para mejorar la eficiencia del gobierno social v. sobre todo Henry B. Hansmann y Reinier KRAAKman, What is Corporate Law?, in The Anatomy of Corporate Law: A Comparative and Functional Approach, a cura de Reinier Kraakman et al., Oxford University Press, New York, 2004, pp. 26 e ss.

68 Por último, se detiene de manera interesante sobre este punto clásico de la teoría general P. GIUDICI, La responsabilità civile nel diritto dei mercati finanziari, Giuffrè, Milano, 2008, pp. 21 y ss., observar críticamente que el recurso a la sanción es claramente predominante con respecto del uso de los incentivos. 
experiencia común, además, que cuando el empresario ha entablado negociaciones que no han fructificado todavía en un acuerdo y él se decide a asumir la iniciativa para la presentación de la demanda de admisión al concordato, lo hace sólo para impedir que alguien de entre los acreedores presente una solicitud de quiebra. O por lo menos para retrasar este momento. En efecto, si a la solicitud del tercero sigue la declaración de quiebra, el deudor no tiene el poder de proponer, enseguida, un concordato de quiebra sino tiene que esperar un año (y no puede hacer transcurrir en todo caso más de 2 años del decreto de aprobación del estado pasivo).

El comportamiento del deudor hipotético que ahora se describe se explica plenamente con la teoría de juegos no cooperativos (o competitivos) ${ }^{69}$. En la incertidumbre de cuáles puedan ser las estrategias ajenas, es decir, de los jugadoresacreedores, el jugador-empresario se encuentra frente a un dilema clásico del prisonero: al no tomar la iniciativa - propuesta del concordato - se arriesga a la presentación de solicitud de quiebra de los acreedores que decidan desistir de las negociaciones pero mantiene viva la posibilidad de la formación del acuerdo extrajudicial (una solución que él considera óptima); al tomar la iniciativa antes de que la negociación haya llegado un acuerdo compartido, se arriesga a que el concordato no sea aprobado con la presumible declaración de quiebra consiguiente y, de cualquier modo, en la hipótesis de que sea aprobado, alcanza una solución inferior a la extrajudicial (solución, pues, sub-óptima). Por lo tanto, racionalmente decide no tomar la iniciativa que puede cerrarle el acceso a la solución óptima. Desde el punto de vista de los acreedores considerados individualmente, la solución óptima sería la del pago íntegro y puntual, o, por lo menos, teniendo en cuenta la crisis desde un punto de vista individual, la maximización de las condiciones de un acuerdo extrajudicial: un objetivo que puede comportar un conflicto entre acreedores con diferentes intereses económicos. En la dirección de la negociación, por lo tanto, los acreedores intervienen como partes de un juego no cooperativo - tendecialmente a suma cero $^{70}-\mathrm{y}$ abonan el riesgo de

69 La teoría de juegos se ha abierto camino en el ámbito matemático y económico por el ensayo de John von Neumann y Oskar Morgenstern, The Theory of Games and Economic Behavior, Princeton University Press, Princeton, 1944. La contribución de mayor impacto es notoriamente la del premio Nobel John F. NAsh, Non Cooperative Games, Ph. D. Thesis, Princeton University, May 1950, de la que proceden breves artículos como The Bargaining Problem, en 18 Econometrica 155 (1950); Equilibrium Points in N-Person Games, en 36 Proc. Nat'l Acad.Sci. 48 (1950); NonCooperative Games, 54 Annals of Mathematics 286 (1951). Para la traslación de la teoría de los juegos al derecho se puede hacer referencia a Douglas G. BAIRD, Robert H. Gertner, Randal C. Picker, Game Theory and the Law, Harvard University Press, Cambridge Mass., 1994; y a las rápidas pero eficaces síntesis de Ian Ayres, Playing Games with the Law, en 42 Stan. L. Rev. 1291 (1990) y Stephen W. Salant, Theodore S. Sims, Game Theory and the Law: Ready for Prime Time?, en 94 Mich. L. Rev. 1839 (1996).

70 En la teoría de los juegos un juego a suma cero describe una situación en que el beneficio o la pérdida de un participante resulta perfectamente compensado por una pérdida o por un beneficio de otro participante. Si a la suma total de los beneficios de los participantes se sustrae la suma total de las pérdidas se consigue cero. 
que la negociación pueda naufragar si se manifiesta la falta de consenso, también irracional, por parte de algunos. Los acreedores no pueden tomar la iniciativa de proponer el concordato, - solución que, introduciendo la regla mayoritaria, permitiría eliminar el riesgo de los bateadores libres -, sino solo decidir provocar la quiebra. Esta última solución, a diferencia de la concordada, no es tampoco sub-óptima porque, en realidad, resulta mejor sólo de la del incumplimiento definitivo. Pues los acreedores cooperan con el empresario en la negociación hasta que consideran plausible un acuerdo compartido entre todos y corren el riesgo del bateador libre que presenta la solicitud de quiebra porque no pueden imponer la solución concordada. A la luz de este modelo simple, no es dificil comprender porque en nuestro sistema legislativo el recurso al concordato es limitado y, cuando lo hay, es tardío. Luego la teoría de los juegos enseña que puede existir una situación de equilibrio también en los juegos competitivos (equilibrio de Nash) que se consigue cuando cada individuo que participa en un determinado juego "elige su jugada, de esta manera maximiza su función de pago, bajo la conjetura de que el comportamiento de los rivales no variará a causa de su elección": es decir, también si se conoce la jugada del adversario, el jugador no haría una jugada diferente a la que ha decidido ${ }^{71}$. El presupuesto para alcanzar el equilibrio de Nash es que se puedan compartir las estrategias y que, por tanto, el juego se desarolle sobre la base de una información completa. Para alcanzar el equilibrio hace falta crear las condiciones para que las partes en juego no quieran perseguir la solución óptima individualmente, pero excesivamente peligrosa, si no imposible de alcanzar, y, en cambio, se les induzca a elegir la solución concordada considerada por cada uno sub-óptima, que eliminar o reducir el riesgo de soluciones antieconómicas acaba por maximizar la utilidad del grupo. A tal fin hace falta poner reglas del juego no asimétricas y que faciliten la división de las estrategias.

La solución americana (Bankruptcy Code, § 1121) tiene muchas de estas cualidades. Por un lado, permite tanto al deudor como a los acreedores dar inicio al procedimiento que será de liquidación o de reorganización según el solicitante deposita una petition por el Chapter 7 o por el Chapter 11. Por otro lado y, sobre todo, cuando ha sido presentada una solicitud por un procedimiento de reorganización entre el momento en que ha sido acogida la istancia de admisión (order for relief) y el momento en que ha sido presentado el plan del concordato (filing) - que será sujeto a votación - transcurren algunos meses (y no menos de 120 días) de intensa negociación entre el empresario y los acreedores ${ }^{72}$, salvo que se trate de un procedimiento dirigido por el deudor y éste haya presentado un plan junto con la solicitud. Durante los primeros 120 días (que pueden extenderse hasta 18 meses) al deudor le corresponde un exclusivity period, es decir un término dentro del que sólo

71 El entrecomillado en el texto procede de la voz teoría de los juegos que se encuentra en Wikipedia.

72 Sobre esta cuestión v. Marc S. Kirschner, Dan A. Kusnetz, Laurence Y. Solarsh and Craig S. Gatarz, Prepackaged Bankruptcy Plans: the Deleveraging Tool of the '90s in the Wake of Oid and Tax Concerns, 21 Seton Hall L. Rev. 643 (1991). 
él tiene el permiso de presentar el plan (Bankruptcy code, $\S 1121(\mathrm{~b}))^{73}$. Después del término, el plan lo puede presentar cualquier acreedor (competing plan) ${ }^{74}$. Durante la negociación el patrimonio del empresario puede ser monitorizado por los acreedores con un U.S. trustee de nombramiento judicial, pero se protege de sus acciones individuales: el deudor tiene intacta la facultad de administrar el propio patrimonio (debtor in possession) pero responde de la gestión del mismo como si fuera un trustee (es decir un curador externo); pues son raros los casos en que ha sido nombrado un trustee externo encargado de la gestión ${ }^{75}$. Se explica así de manera bastante fácil también porque las quiebras clamorosas a finales de 2008 están en el candelero - con notable sorpresa de los mercados - sólo cuando los deudores han decidido dirigir los procedimientos de reorganización: incluso Lehman Bros., aunque la gravedad de la exposición no ha permitido encontrar un acuerdo de tipo conservativo y se quiere proceder a la liquidación ${ }^{76}$. Probablemente no es necesario prever dos distintos procedimientos, de reorganización y de liquidación, cuando el presupuesto para el acceso a los dos es lo mismo. Así en Alemania ${ }^{77}$, como en España ${ }^{78}$ y también en la legislación rusa ${ }^{79}$, la solicitud que permite el acceso a un procedimiento concursal no

73 V. Richard F. BRoude, Reorganization under Chapter 11 of the Bankruptcy Code, ALM, New York (leave loaf ed.), 1986-2005, § 8.4, \} 8-4.

74 El Tribunal Supremo de los Estados Unidos difunde un libro blanco sobre los procedimientos de insolvencia (v. http://www.uscourts.gov/bankruptcycourts/bankruptcybasics/chapter11.html). Sobre el exclusivity period afirma que el derecho reconocido a los acreedores de presentar un plan competidor constituye un incentivo para el deudor que puede presentar el plan dentro del término de exclusivity y sirve de disuasivo a los excesivos retrasos en la solución de la crisis (The creditors right to file a competing plan provides incentive for the debtor to file a plan within the exclusivity period and acts as a check on excessive delay in the case).

75 Las del texto son todas informaciones fácilmente extraíbles del mencionado libro blanco de la Corte Suprema (v. nt. 74). Es útil la lectura de algunas deducciones: «the appointment or election of a trustee occurs only in a small number of cases. Generally, the debtor, as "debtor in possession,» operates the business and performs many of the functions that a trustee performs in cases under other chapters. 11 U.S.C. § 1107(a) [...]. Section 1107 of the Bankruptcy Code places the debtor in possession in the position of a fiduciary, with the rights and powers of a chapter 11 trustee, and it requires the debtor to perform of all but the investigative functions and duties of a trustee».

76 Para una explicación exhaustiva v. Jason KILBORN, Lehman Chapter 11 = Reorganization?, del 15 de septiembre de 2008 que se encuentra en http://ucclaw.blogspot.com/2008/09/lehmanchapter-11reorganization.html (consultado por último el 8 de septiembre de 2009).

77 La Sanierung es una reorganización que puede ser solicitada sólo por los acreedores ( $\$ 157 \mathrm{InsO}$ ).

78 En España, sin embargo, el acreedor no puede conseguir la apertura del concurso cuando la insolvencia es sólo inminente. La solución ha sido criticada por asímetrica por parte de A. RoJo, op. cit., pag 176.

79 Durante la primera asemblea de acreedores se decide el procedimiento de quiebra más adecuado a las circunstancias. Algunos tienen finalidad conservativa, es decir, el saneamiento financiero (financavoe ozdorovlenie) y el saneamiento judicial (sudebnaja sanacija o vnešnee upravlenie). Ambos son procedimientos concorsuales que quieren restablecer la capacidad del deudor de efectuar regularmente los pagos (platez'esposobnost') por medio de la moratoria de los pagos: mientras la primera (artt. 76-92 zakon o nesostojatel'nosti) está subordinada a una financiación (externa o de los socios de las personalidades jurídicas insolventes) idonéa para permitir al deudor sanear la situación financiera; la segunda (artt. 93-123 zakon o nesostojatel'nosti) se traduce en una 
cierra ninguna salida del mismo procedimiento. Conseguido el amparo protector e implicados todos los acreedores en la búsqueda de una solución para la superación de la crisis de la empresa, la solución concordada (Sanierung en Alemania, convenio en España, mirovoe soglašenie en Russia) resultará preferida todas las veces que pueda localizarse en breve un acuerdo más ventajoso para todos con respecto a la hipótesis de liquidación. En todo caso, la liquidación es la solución del procedimiento a falta de un acuerdo sin la necesidad de ningún ulterior acto de impulso.

Estas experiencias comparadas evidencian lo que es -el resultado de esta reflexión- el obstáculo más importante para la solución del concordato preventivo, es decir, la incapacidad del deudor y de los acreedores fuertes no de imponer ya una solución, sino un tablero de comparación que decide en breve lo que hacer y que lo haga la mayoría. Probablemente, asegurar a las partes que asumen el mayor riesgo del naufragio de las negociaciones (de un lado el deudor y del otro los acreedores más expuestos) un instrumento para imponer una negociación que el bateador individual libre no pueda impedir, constituiría el incentivo que se antoja necesario para que se inviertan estadísticamente los números de los concordatos con respecto a los de las quiebras. Con todas las objeciones que se pueden oponer a este análisis, indudablemente superficial, el mismo parece proporcionar una primera indicación del camino que el legislador puede recorrer si quiere revalorizar un instituto que en otro lugar desarrolla una función fundamental y que, en cambio, aquí es poco significativo. De los principios contenidos en una ley de delegación se pueden proponer algunas intervenciones sobre los siguientes puntos esenciales: a) eliminar la asimetría entre acreedores y deudor con la posibilidad de proponer el concordato para permitir a los acreedores evidenciar la crisis y, si se quiere, ya desde cuando ésta se manifiesta en una forma curable; b) al mismo tiempo el deudor tiene que probar que la crisis no existe y ofrecer garantías sobre el regular cumplimiento de las obligaciones asumidas; c) una vez abierto el procedimiento, fijar un término breve para la formación del pasivo (según reglas más agiles si el concordato ha sido propuesto por el deudor) y prever que el plan - si no ha sido ya preempaquetado pueda ser presentado dentro de un término dilatorio que obligue las partes a negociar

gestión temporal de la empresa por parte de un vnešnyj upravljajus c $^{`} i j$, según un plan redactado por él mismo y aprovechado por los acreedores (art. 106 zakon o nesostojatel'nosti). Respecto a éstas, la alternativa es el procedimiento de gestión concursal (konkursnoe proizvodstvo), que tiene finalidad liquidatoria. La gestión concursal viene precedida por la declaración de quiebra por parte del tribunal (priznanie bankotstvom) (art. 74 zakon o nesostojatel'nosti) y está confiada a un curador concursal (konkursnyj upravljajus ${ }^{2}$ ¿ ij), que realiza el activo y lo divide proporcionalmente entre los acreedores con el respeto de las causas legítimas de prelación y del orden de prioridad indicado en el art.25, inciso 3, graz danskij kodeks RF. En cualquier momento del procedimiento concursal, sin embargo, puede haber un concordato (mirovoe soglašenie), entre el deudor y la mayoría de los acreedores expresada en asemblea sujeta a homologación del tribunal (artt. 150-167 zakon o nesostojatel'nosti). Para otras indicaciones permítaseme remitir a N. DE LuCA, Impresa e società nella Russia post-sovietica, in RDS, 1/2007, 140, espec. a la pp. 171 y ss. 
bajo el amparo protector del procedimiento; d) legitimar también los acreedores a formular una propuesta de concordato después del término dilatorio como en el concordato de quiebras; e) introducir también el mecanismo de adopción de decisiones del concordato de quiebras al considerar favorables todos los votos no expresados para facilitar la formación del acuerdo y evitar el oportunismo dictado por el desinterés de algunos; f) prever que el fracaso de las negociaciones concordadas dentro de un tiempo determinado determina sin la necesidad de un impulso ulterior, la liquidación del patrimonio necesario por el pago de las deudas; g) prever que esa liquidación tenga lugar de forma voluntaria por parte del deudor cuando la crisis no tiene los rasgos de la insolvencia mientras que se desarrolle según las reglas de la quiebra cuando se verifica la insolvencia a instancia de quien tiene el interés de hacerla evidente sin solución de continuidad; h) eliminar la duplicación de disciplina y acoplar a las del concordato preventivo las disposiciones sobre el concordato de quiebra con las oportunas distinciones. 